\title{
Empirical Models of Firms and Industries
}

\author{
Victor Aguirregabiria \\ Department of Economics \\ The University of Toronto and CEPR \\ Margaret Slade \\ Vancouver School of Economics \\ The University of British Columbia
}

April 25, 2017

\begin{abstract}
We review important developments in Empirical Industrial Organization (IO) over the last three decades. The paper is organized around six topics: collusion, demand, productivity, industry dynamics, interfirm contracts, and auctions. We present models that are workhorses in empirical IO, and describe applications. For each topic, we discuss at least one empirical application using Canadian data.
\end{abstract}

Keywords: Empirical IO; collusion, demand for differentiated products; production functions; dynamic structural models; interfirm contracts, empirical auction models.

JEL codes: C57, L10, L20, L30, L40, L50

Victor Aguirregabiria. Professor of Economics. Address: 150 St. George Street. Toronto, ON, M5S 3G7, Canada. Phone: (416) 978-4358. E-mail: victor aguirregabiria@utoronto.ca

Margaret Slade. Professor of Economics Emeritus. Address: 6000 Iona Building 141-B. Vancouver, BC, V6T 1Z1, Canada. E-mail: mslade@mail.ubc.ca 


\section{Introduction}

Thirty years ago, The Empirical Renaissance in Industrial Economics, (Bresnahan and Schmalensee, 1987, eds.), was published! That volume demonstrated how empirical research into industrial organization (IO) had moved away from the use of industry cross sectional data, as was prevalent in the earlier structure-conduct-performance literature, and towards the use of more disaggregate firm level panel data. Moreover, many of the topics that are featured in that volume are also covered here. Although we also discuss research that was published more than 30 years ago, we emphasize the period since that time.

A lot has happened in 30 years. However, three developments have played a key role in the evolution of empirical work in IO during that period. The first is the availability of very large and detailed data sets, such as panel data on establishments and households; the second is the development of econometric techniques that enabled estimation of more sophisticated and richer models; and the last is the availability of vastly increased computing capacity and speed that allowed the first two to be combined. Although we do not focus on these developments, one should bear in mind that, without them, much of the research that we discuss would not have been possible.

Our mandate in writing this survey was to cover areas of empirical IO in which Canadians have made significant contributions. On the one hand, that made our job very easy, since Canadians have made significant contributions to all areas of empirical IO. On the other hand, it made our job very hard, since there were too many topics from which to choose. In the end, we chose to cover six applied areas: the demand for differentiated products, tacit and overt collusion, productivity measurement, dynamic discrete choice, interfirm contracting, and auction models. With each of those areas, we discuss general issues and questions, mention some seminal papers, give a flavor of the findings from many studies, and suggest areas where future research is needed. Furthermore, for each topic, we discuss at least one empirical application that uses Canadian data. Due to space constraints, we did not try to be comprehensive, either with respect to the choice of topics or to the choice of research to discuss within each topic, and we apologize to all those excellent researchers whose work we have neglected.

\section{Demand for Differentiated Products}

Traditionally, empirical demand models were estimated with relatively aggregate data and focused on substitution and complementarity between broad product classes (e.g., food, housing, and clothing). Moreover, many such studies were based on flexible functional forms that place no restrictions on own and cross price elasticities. Those models were tractable because the number of products was small. However, with the advent of much more disaggregate data, applied economists have

\footnotetext{
${ }^{1}$ This was a special issue of The Journal of Industrial Economics and a book.
} 
tended to focus on individual industries and the substitute products that they produce. Although the abundance of data has been a boon, it has also created problems; in particular, there are too many products. For example, there are hundreds of automobile models and brands of beer. The most common method of circumventing this problem has been to focus on a small set of characteristics (e.g., horsepower, fuel efficiency, and size) in the spirit of Lancaster (1978) and to assume that products are bundles of characteristics, which are the things that consumers really care about. In other words, the large dimensional space of products can be projected into the much smaller dimensional space of characteristics, thereby achieving tractability.

Most models of the demand for differentiated products are cast in a discrete choice framework in which each consumer chooses the product or bundle of characteristics that maximizes its utility. We therefore discuss those formulations before turning to some alternatives. We then ask two questions: where do consumer preferences come from and how are product locations chosen.

\subsection{Discrete Choice Demand Models}

The most popular discrete choice demand model is developed in Berry, Levinsohn, and Pakes (1995, BLP). That model builds on the familiar logit and overcomes some of its shortcomings, in particular the restricted nature of substitution patterns that the logit implies. With the logit, there is no notion of closeness in product characteristic space and cross price elasticities are determined by market shares (see, e.g., Berry, 1994). We describe the BLP model below and then discuss some extensions.

We observe $M$ markets in $T$ time periods. However, we suppress $t$ and $m$ subscripts for expositional purposes. Suppose that there are $I$ consumers indexed by $i$ and $J$ product characteristics indexed by $j$. Consumer $i$ receives utility $u_{i j}$ from purchasing product $j$ according to

$$
u_{i j}=x_{j} \beta_{i}-\alpha_{i} p_{j}+\xi_{j}+\epsilon_{i j}
$$

where $x_{j}$ is a $K$ dimensional row vector of observable product characteristics, $p_{j}$ is price, $\xi_{j}$ is an unobservable product characteristic (often quality), and $\epsilon_{i j}$ is a mean zero stochastic term. The coefficients $\alpha$ and $\beta$ are modeled as random coefficients that can, in principle, have any multivariate distribution. However, it is standard to model them as independent normals,

$$
\left[\begin{array}{c}
\alpha_{i} \\
\beta_{i}
\end{array}\right]=\left[\begin{array}{c}
\alpha \\
\beta
\end{array}\right]+\Pi z_{i}+\Sigma \nu_{i}, \quad \nu_{i} \sim N\left(0, I_{K+1}\right),
$$

where $z_{i}$ is a vector of observable characteristics of consumer $i$, such as demographics, $\Pi$ is a matrix of coefficients to be estimated, $\nu_{i}$ is a vector of unobservable consumer attributes, and $\Sigma$ is a scaling matrix. Finally, there is an outside good, $j=0$, whose utility is often normalized to zero.

One can aggregate the individual choices into a product level demand equation as follows

$$
s_{j}=\int_{A_{j}} d P_{\epsilon}(\epsilon) d P_{\nu}(\nu) d P_{z}(z)
$$


where $s_{j}$ is the market share of product $j$, the $P$ 's are population distribution functions and $A_{j}$ is the set of individual specific variables that lead a consumer to choose alternative $j: A_{j}=\left\{\left(\epsilon_{i}, \nu_{i}, z_{i}\right)\right.$ :

$\left.u_{i j}>u_{i \ell} \quad \forall \quad \ell \neq j\right\}$. Since the integral in (3) is intractable, the model is often approximated using simulation methods. Furthermore, the unobserved product characteristic, $\xi$ (quality), is apt to be correlated with price, implying the need for instruments. Once the integral has been approximated, moment conditions can be specified.

With the BLP model, unlike the logit, the interaction between product characteristics, $x$, and consumer characteristics, $z$ and $\nu$, introduces a notion of distance, which implies that products that are closer to one another in product characteristic space (e.g., two compact cars), are closer substitutes for one another.

The BLP demand model is usually imbedded in an industry supply/demand framework that incorporates imperfect competition, which is often assumed to be a differentiated products Bertrand game. There have been many applications of this model, including Nevo (2000), that looks at mergers in the breakfast cereal industry, and Petrin (2002), that assesses the welfare implications of the introduction of a new product in the automobile industry, the minivan.

The BLP model requires enough moments to identify not only prices but also the distributional parameters, which can be hard to find with only market level data, particularly if there is only one market and time period. However, micro moments can sometimes be used to overcome this problem. For example, Petrin (2002) suggests using micro data that provide information on the joint distribution of consumer and product characteristics. In addition, Berry, Levinsohn, and Pakes (2004) augment market level data with data on individual first and second choices.

\subsection{Other Formulations}

Although it is the dominant paradigm, not all differentiated product demand models involve singleunit discrete choices. In this subsection, we discuss two continuous choice formulations that involve restrictions on flexible functional forms and then turn to discrete continuous and multiple discrete choices.

Hausman, Leonard, and Zona (1994) specify a three stage demand system based on Gorman (1971) multi-stage budgeting approach. The stages are: i) aggregate demand for the product (beer); ii) demand for each segment (premium, light, and popular); and iii) demand for brands within segments. Estimation proceeds in reverse order. The specification at the lowest level is the 'almost ideal demand system' of Deaton and Muellbauer (1980), which is flexible, whereas the upper two stages use log log formulations.

In contrast, Pinkse and Slade (2004) specify a demand system that is based on the normalized quadratic indirect utility function of Berndt, Fuss, and Waverman (1977) and McFadden (1978), which is also flexible, combined with the distance metric approach developed in Pinkse, Slade, 
and Brett (2002). The normalized quadratic yields a linear demand system with matrix of price coefficients $B=\left[b_{i j}\right]$. Pinkse, Slade, and Brett assume that the coefficients depend on measures of the distance between brands in product characteristic space, $b_{i j}=g\left(D_{i j}\right)$, where $D_{i j}$ is a vector of distances, such as the absolute value of the difference in alcohol contents or whether two brands of beer belong to the same segment (lager, ale, or stout). Finally, the function $g()$ is estimated semiparametrically. With this specification, a notion of closeness among brands is introduced directly.

Both of these demand models are parsimonious while retaining substantial flexibility. Furthermore, in the applications, both are embedded in a model of industry equilibrium and used to evaluate beer industry mergers, the first in the US and the second in the UK.

There are also hybrid models in which consumers make discrete/continuous choices; they decide which brand to purchase followed by a choice of how many units to buy, where the latter can be a discrete or continuous number. Consumers can also purchase more than one brand. In other words, they can make multiple discrete choices, which is denoted multiple discreteness. Hendel (1999) develops a model that incorporates both aspects, multiunit and multibrand choices. In the application, he assumes that purchasers make decisions for multiple divisions of a firm (purchases of computers) and that each division orders multiple units of a given brand, where the choice of brand depends on the tasks that the division performs.

Dube (2004) applies Hendel's specification to model purchases of carbonated soft drinks. With grocery shopping, multiple discreteness occurs for two reasons: households can have more than one member and those members can consume soft drinks on more than one occasion. Dube (2005) applies the multiple discrete demand model to evaluate mergers in the US soft drink industry.

\subsection{Modeling Consumer Preferences}

With most BLP type models, consumer tastes are random draws from some multivariate distribution, and market shares are integrals over the unobservables, which include consumer characteristics. Furthermore, the interaction of consumer and product characteristics implicitly defines a notion of closeness such that, when the price of a most preferred product rises sufficiently, an individual chooses a substitute that is 'close' to the original choice. In some cases, however, it is desirable to be explicit about consumers' locations in characteristic space and the associated distances between products and consumer tastes. The way in which this is done depends on whether those locations are observable or unobservable.

Geographic location is the most common consumer observable that is used to construct an explicit measure of distance. For example, Davis (2006) studies demand for movie theaters and considers a utility function $u_{i f h}=x_{f h} \beta-g\left(D_{i h}\right)+\xi_{f h}+\epsilon_{i f h}$, where $h$ is the index for movie theater, $f$ is the index for film, $x_{f h}$ includes both film and theater characteristics, and $D_{i h}$ is the Euclidean 
distance between consumer $i^{\prime} s$ residence and theater $h^{\prime} s$ location. With this specification, consumer heterogeneity is determined solely by location, which is a point in geographic space.

\section{An Application from Québec City}

Houde (2012) develops an interesting variant of the geographic location model. Products are gasoline stations with locations indexed by $\ell$. Consumers, however, do not 'reside' at a point. Instead, consumer locations are their entire commuting paths, where commuting paths are the routes that minimize the travel time between home and work locations. Denote by $r(o, d)$ the shortest route between home or origin, $o$, and work or destination, $d$, and let $t(o, d)$ be the associated travel time. Then the distance between an individual's commute path and a service station located at $\ell$ is $D(r(o, d), \ell)=t(o, \ell)+t(\ell, d)-t(o, d)$, i.e., the driving time required to deviate from the shortest route in order to purchase gasoline at station $\ell$. Consumers weigh transport costs for each station against differences in posted prices and other station characteristics in determining their optimal choices. This spatial model is estimated using panel data on the Québec City gasoline market and the estimated model is used to evaluate a vertical merger. Houde finds that, compared to a model in which consumers reside at a point, competition is much less localized, since motorists can substitute among stations that are far from one another but close to their commuting paths. This means that there is less differentiation and more intense price competition. He also finds that markets are broader since, for example, price competition spills across suburbs, where consumers live, and the central city, where they work.

In many instances, however, consumer locations are not known. In particular, this is usually the case when products are located in a more general characteristic space. One solution to the problem is to modify the BLP model in (1) to include Hotelling (1929) 'transport' costs. Let consumer $i$ 's location (that is unknown to the researcher) be a $K$-dimension vector $\ell_{i}$, and define $i$ 's utility as $u_{i j}=x_{j} \beta-\alpha_{i} p_{j}+\xi_{j}-\sum_{k=1}^{K} \gamma_{k}\left(x_{j k}-\ell_{i k}\right)^{2}+\epsilon_{i j}$, where $\gamma$ is a vector of disutilities that are incurred when product $j$ differs from $i$ 's ideal product. This specification differs from other formulations that we have discussed in that the latent utility index is nonlinear in the random coefficients. Moreover, since $\xi_{j}$ is an unobserved product characteristic, it could enter the quadratic portion of utility. However, results to date for nonparametric identification of discrete choice models (e.g., Fox, Kim, Ryan, and Bajari, 2011, 2012; Berry and Haile, 2014) are for linear index models and/or models that are monotonic in $\xi_{j}{ }^{2}$

\subsection{Endogenous Product Characteristics}

We have discussed differentiated product demand models in the context of exogenous product characteristics. At an earlier stage, however, firms choose where to locate their products in characteristic

\footnotetext{
${ }^{2}$ Although Berry and Haile's results are very general, they do not show identification of the distribution of the random coefficients, even when $\xi$ is additively separable.
} 
space. Some of the more recent literature on endogenous locations is surveyed in Crawford (2012), who notes that there are two aspects to the problem of location choice: how many products to produce and what characteristics those products should possess. The first is more standard because the decision to offer a product is similar to the decision to enter a market, as in, e.g., Bresnahan and Reiss (1991). However, most researchers add supply/demand profitability conditions to a typical entry model and estimate a two-stage game. For example, in the first stage, players decide which and/or what sort of products to offer and in the second, they engage in price competition.

When products are discrete, researchers tend to focus on product selection. For example, Draganska, Mazzeo, and Seim (2009) estimate a two stage game that endogenizes both the variety and the prices of ice cream products, and Sweeting (2013) assesses the choice of radio formats to offer in a dynamic context.

When the set of products cannot be easily changed, researchers tend to focus on the continuous choice of characteristics, sometimes just one - quality. If preferences are strictly vertical, each good competes only with its two nearest neighbors, as in Bresnahan (1987). However, most researchers also include some aspects of horizontal differentiation. Moreover, some researchers cast their problem in a monopoly framework, whereas others consider an oligopoly. Since the latter group is more relevant for our survey, we discuss some of that research.

Many of the oligopoly quality choice studies assess product repositioning after a change such as entry or a merger. In particular, price, quality, and/or horizontal characteristics can be altered in response to such a change. To illustrate, Chu (2010) looks at the effect of satellite entry on cable television providers. The setting is a one-shot Stackelberg game with satellite as the first mover. Fan (2013) assesses repositioning of newspapers after a merger. Her model is a two-stage game with quality and other characteristics chosen first, followed by the choices of newspaper and advertising prices.

In a somewhat different vein, Pinkse, Slade, and Brett (2002) construct endogenous distances, rather than locations, in product characteristic space. To illustrate, outlet $j$ is defined to be the exogenous closest geographic neighbor of outlet $k$ if the Euclidean distance between $j$ and $k$ is less than that between $k$ and any other outlet. In contrast, $j$ is $k$ 's endogenous closest neighbor if $k$ 's delivered price at $j$ 's location is lower than at any other outlet's location. When locations or distances are endogenous, ingenuity is required to come up with valid instruments. In particular, a standard set of instruments for price, the characteristics of rival products or 'BLP' instruments, cannot be used. In our view, endogeneity of preferences and of product locations are areas where more research is needed before we can have a good understanding of the effects of policy changes. 


\section{Collusion}

Collusion has many definitions. We use the term, however, in the game theoretic sense - obtaining an outcome that is preferred by firms to the Nash equilibrium of the one-shot competition game. Collusion can be overt or tacit and it is often difficult to distinguish between the two empirically. However, unless overt collusion is legal (e.g., an export cartel), it requires enforcement mechanisms that are similar to those that can be used by tacitly colluding firms. For this reason, we make no clear distinction between the two.

Empirical studies of tacit collusion are somewhat older than much of the research that we discuss, dating at least back to Iwata (1974). However, there has been a recent resurgence of interest in the topic. Moreover, although most of the early studies were of homogeneous products, many recent applications involve firms that produce differentiated products. After discussing both classes of studies, we turn to an issue that has received much attention in Canada; the implications of cycles in retail gasoline markets for collusion and the competitiveness of those markets.

\subsection{Collusion with Homogenous Products}

Early studies of tacit collusion were concerned with measuring the outcome of a game without specifying that game. In particular, researchers asked how far the industry outcome was from some benchmark, which might be perfect competition or Cournot. In that literature, outcomes are summarized by a conduct parameter or parameters, $\Theta$, that can be industry wide or firm specific.

To illustrate, suppose that industry output is $Q$, inverse demand is $P=p(Q)$, and the output and marginal cost of firm $i$ are $q_{i}$ and $c_{i}$, respectively. In a Cournot game, firm $i$ 's first-order condition can be rearranged to yield $P=c_{i}-q_{i} p^{\prime}(Q)$. If instead one remains agnostic about the game, the first-order condition can be modified to include a conduct parameter, $\Theta_{i}$ as follows ${ }^{3}$

$$
P=c_{i}-\Theta_{i} q_{i} p^{\prime}(Q) \text {. }
$$

Equation (4) nests perfect competition $\left(\Theta_{i}=0\right)$, Cournot $\left(\Theta_{i}=1\right)$ and perfect collusion in an $N$ firm symmetric oligopoly $\left(\Theta_{i}=\mathrm{N}\right)$. Furthermore, (4) can be rearranged to yield the price cost margin, $\left(P-c_{i}\right) / P=\Theta_{i} / \eta_{i}$, where $\eta_{i}$ is the elasticity of the firm's demand. In other words, $\Theta_{i}$ is the elasticity adjusted margin.

To implement such a model, one can estimate the first-order conditions jointly with demand and cost equations. Furthermore, in the absence of data on costs, one can specify a game (a value of $\Theta$ ) and solve the first-order conditions for implicit marginal costs - those that rationalize the choice of $\Theta$. Finally, one can identify cost and conduct jointly by including shifters of the demand elasticity,

\footnotetext{
${ }^{3}$ Many researchers aggregate the individual-firm first-order conditions and estimate an industry $\Theta$ from the relationship $P=c-\Theta Q p^{\prime}(Q)$. With this specification, conduct ranges from $\Theta=0$ (perfect competition) to $\Theta=1$ (perfect collusion).
} 
e.g., variables that rotate demand (Bresnahan, 1982). This can be accomplished, for example, by considering supply shocks (Bresnahan, 1987) or multiple pricing regimes (Porter, 1983).

Many static conduct models have been estimated and applied to evaluate not only the collusiveness of markets (Brander and Zhang, 1990) but also such issues as the competitive effects of entry (Spiller and Favaro, 1984), nonprice competition (Roberts, 1984), or capacity constraints (Brendstrup, Paarsch, and Solow, 2006).

Modified conduct models have also been used to assess the predictions of specific dynamic games. For example, Porter (1983) tests the Green and Porter (1984) model of tacit collusion in which demand is stochastic and only an imperfect signal of price is observed. As a consequence, when a low signal is received, players cannot distinguish between a bad demand shock and cheating by a rival. Punishment (Nash reversion) will therefor be observed periodically. Porter evaluates the timing and duration of price wars among transporters of rail freight using a simultaneous switching regression model with periodic reversion from collusive to Bertrand behavior.

Not all price wars, however, can be explained by lack of observability of the choice variable. For example, despite the fact that prices are posted and thus easy to observe, price wars are common phenomena in retail gasoline markets. Slade (1989) models price wars in such markets as learning about new demand conditions after a large shock, and Slade (1992) evaluates that model using data from a price war in Vancouver. In particular, slopes of intertemporal reaction functions are latent variables, the system is estimated via the Kalman filter, and different dynamic games correspond to different transition matrices for the latent variables.

Somewhat later, the use of conduct parameters to assess market power came under attack and, as a result, temporarily fell from favor. In particular, Corts (1999) argued that no inference on the extent of market power can be made without specifying underlying behavior. Although he notes that researchers have been careful to separately identify costs and conduct, the map between equilibrium variation and the equilibrium value of the elasticity adjusted price cost margin is fraught with problems. In particular, the mapping is not valid unless average and marginal responses of margins to demand shifters are the same.

In an assessment of the actual as opposed to the potential bias in conduct models, Genesove and Mullin (1998) use data on observed costs and margins in the sugar refining industry, an industry with a very simple fixed coefficient technology, as benchmarks with which to compare an estimated model. They find that estimated and actual costs and margins are quite close, which is taken as support of atheoretical conduct models.

\subsection{Collusion with Differentiated Products}

Perhaps because identification of costs and conduct is more complex when products are differentiated, the study of market power in such industries came later. Nevo (1998) studies identification 
in multiproduct industries that produce differentiated substitutes and notes that, in addition to instruments that rotate the demand equation, as in Bresnahan (1982), there must now be demand shifters whose number grows with the number of products. Given that such a large number of exclusion restrictions is difficult to satisfy in practice, he advocates a menu approach in which different values of conduct parameters that correspond to different games are specified a priori and fit is compared using tests of non-nested models, as in Gasmi, Laffont, and Vuong (1992).

To implement his approach, Nevo (2001) uses data on ready-to-eat breakfast cereals, an industry that is characterized by high concentration, multiproduct production, and heavy advertising, to assess various models. To illustrate, suppose that $N$ firms produce $J$ differentiated products with $N \leq J$. One can decompose the estimated price cost margins into three factors. The first, which is due to differentiation alone, are the margins that are associated with the Nash equilibrium of the $J$ single-product-firm game. The second, which is due to multiproduct production, is the increase in margins that are associated with the Nash equilibrium of the $N$ multiproduct-firm game in which players internalize the externalities on own product sales that result from changes in own prices. The third is the remainder, which is interpreted as due to tacit collusion. He specifies a demand equation that combines elements of the Berry, Levinsohn, and Pakes (1995) model with panel data methods and finds support for the Bertrand equilibrium of the multiproduct-firm game. In other words, there is no evidence of tacit collusion.

Slade (2004) uses a similar decomposition to assess unilateral and coordinated effects (joint dominance) in the UK brewing industry. Using the distance semiparametric demand model developed in Pinkse and Slade (2004), she finds no evidence of joint dominance. Note that the decomposition used in the papers by Nevo and Slade relies on exogenous cost data for comparison purposes $4^{4}$ Indeed, they do not use non-nested hypothesis tests to discriminate among models because they have something with which to compare the estimated models.

More recently, Berry and Haile (2014) demonstrate nonparametric identification of a broad class of random utility models that includes those that discriminate among alternative models of conduct. Moreover, in contrast to the earlier focus on demand rotations, they show that there is a much broader range of cross-market and cross-firm variation that can be exploited. Specifically, they show that identification requires instruments that generate exogenous variation in choice sets including exogenous variation in markups. Such instruments can be exogenous changes in the number of firms, in the characteristics of products, and in the costs of competitors.

A number of recent studies have estimated more general conduct models for differentiatedproduct markets. We discuss three examples that study different markets and questions. All three of these studies eschew an attempt to estimate the mode of competition (e.g., Bertrand versus Cournot) and they overcome the Corts (1999) critique by specifying Bertrand competition and

\footnotetext{
${ }^{4}$ In other words, they use observed margins to assess the unexplained residual.
} 
identifying conduct parameters conditional on that hypothesis.

The first, Ciliberto and Williams (2014), asks how multimarket contact, a notion that is formalized in Bernheim and Whinston (1990), facilitates tacit collusion in airline markets. However, they do not model conduct as a matrix of free parameters, which would limply a need for instruments whose number grows with the number of products. Instead, they model conduct as a function of multimarket contact between firm pairs, where contact is defined as the total number of markets that two firms serve concomitantly. Building on Berry and Haile (2014), they use cross sectional variation in that variable to identify the conduct parameters. Their estimated model provides strong support for the hypothesis that contact facilitates collusion.

In the second study, Miller and Weinberg (2016) investigate how mergers in the US brewing industry facilitate tacit collusion. They postulate that competition was Bertrand prior to the merger and include an industry wide conduct parameter, $\Theta$, to capture increases in collusion post merger. Furthermore, in addition to more conventional instruments, they use the merger itself as a shifter. In their application to the Miller Coors joint venture, they find that the joint venture led to significant increases in collusion. Moreover, they decompose their estimated price increases into portions attributable to unilateral effects, coordinated effects, and merger-specific efficiencies.

The third study, Michel (2016), also looks at mergers and uses the merger itself as a shifter. However, Michel performs the converse exercise, assuming that the conduct parameter does not change post merger and estimating pre-merger conduct. Rather than specifying a conduct parameter as in equation (4), however, collusion between brand pairs owned by different firms is treated as a parameter, $\lambda$, that captures the degree to which firm $i$ takes into account firm $j$ 's profit in choosing its prices $5^{5}$ In other words, the conduct parameter is modeled as part of the firm's objective function rather than as a behavioral response. Finally, in addition to estimating conduct, the speed and intensity of organizational integration are assessed by examining the extent to which merging firms jointly maximize internal profits after a merger.

\subsection{Can Collusion Explain Unusual Price Patterns?}

Some industries experience unusual price patterns such as cycles and economists often ask if those patterns are evidence of collusion. We illustrate with a discussion of studies that examine price cycles in retail gasoline markets.

\section{Applications from Canadian Cities}

The asymmetry of gasoline price responses to crude oil price changes, with rapid increases and slow declines, has been noted by many researchers (e.g., Bacon, 1991, Borenstein, Cameron, and Gilbert, 1997). However, most of that literature imposed little structure implied by theory. Eckert

\footnotetext{
${ }^{5}$ This is similar to what is done in the cross-shareholding (Boll and Guth, 1992) and joint venture (Reynolds and Snapp, 1986) literatures.
} 
(1999), in contrast, notes that some Canadian cities experience price cycles whereas others do not, and proposes that the two patterns - constant price and cyclical equilibria — can be explained by Edgeworth cycles as developed in Maskin and Tirole (1988b). Moreover, he introduces the notion of large and small firms and explores the relationship between the presence of independent stations and the existence of cycles. In particular, he demonstrates that, if the fraction of small firms is sufficiently large, only cyclical equilibria exist. Eckert (2003) tests this explanation using data from Canadian cities and finds support for his hypothesis. Noel (2007) explores the same

issue and specifies a Markov switching regression to estimate the prevalence of the different pricing regimes across Canadian cities. He finds that cycles are more prevalent, and are accelerated and amplified, when there are more small firms in the market. Taken together, these studies support the hypothesis that cycles are evidence of noncooperative behavior.

Not all studies, however, conclude that cycles are not evidence of overt collusion. In particular, Clark and Houde (2014) show that cyclical pricing in some cities in Québec was collusive, with margins that were higher than those in other cities, that the high-margin markets exhibited asymmetric price adjustments to cost changes, and that the asymmetric pattern, as well as the high margins, collapsed after the Canadian Competition Bureau launched an investigation into collusion in those cities. Moreover, Clark and Houde point to explicit communication as a facilitator of equilibrium selection in those markets and use documents to support their claim.

Turning to the US, Deltas (2008) finds a positive relationship between margins and asymmetric response, whereas Lewis (2009) concludes that the high retail margins that were experienced after Hurricane Rita dissipated more quickly in cities with cyclical pricing. The association between cyclical pricing and collusion is therefore an unsettled issue.

Finally, Wang (2009) explores a previously untested feature of the Maskin and Tirole (1988b) model - that firms play mixed strategies at the bottom of the cycle to determine who will lead the price upwards. Using data from Australia, he confirms that price leadership is better predicted by mixed strategies. It therefore appears that, at least in some markets, Edgeworth cycles explain the data well.

\section{Production Functions and Productivity}

Productivity, which is broadly defined as a measure of output divided by a measure of inputs, is important for economic growth and for industry and firm competitiveness. In this section, we discuss various ways to measure productivity and its rate of growth as well as applications that use those measures. The productivity literature is vast and we limit attention to methods that are based on a production function. 


\subsection{Index Numbers}

Perhaps the simplest way to estimate total factor productivity is to calculate an index number, since this does not involve econometric estimation. To illustrate, suppose that we have a production function $y=f(x)+\omega$, where $y$ is output, $\omega$ is the state of technology, $x$ is a vector of inputs, and all variables are in natural logarithms. Define $\Delta y_{t}=y_{t}-y_{t-1}, \Delta \omega_{t}=\omega_{t}-\omega_{t-1}$, and $\Delta x_{t}=$ $\sum_{k} s_{k t}\left(x_{k t}-x_{k t-1}\right)$, where $s_{k}$ is the $k$ th input's share in revenue. Under the assumptions of constant returns to scale (CRTS) and competitive pricing in the output market ${ }^{6}$ Jorgenson and Griliches (1967) show that total factor productivity growth, $\Delta \mathrm{TFP} / \mathrm{TFP}$ is $\Delta y_{t}-\Delta x_{t}=\Delta \omega_{t}$. Indeed, the rate of growth of TFP, which is the rate of technical change, is a back-of-the-envelope calculation.

Although this is a straight-forward and simple formulation, it relies on a number of restrictive assumptions, not only CRTS and competitive pricing but also all factors must be in long run equilibrium. For this reason, most index number productivity studies rely on a cost function, which overcomes the first two limitations, a variable cost function, which also overcomes the third, or some other formulation.

Much of the pioneering work in index number measures of productivity was done by Canadian economists, most notably Erwin Diewert. However, IO economists have tended to rely on econometric estimation of production functions. Nevertheless, index number formulations have proved to be useful tools in IO. A typical study regresses a TFP index on factors that are hypothesized to influence productivity. For example, Lychagin, Pinkse, Slade, and Van Reenen (2015) regress TFP indices on own and rival $R \& D$ expenditures, and they decompose $R \& D$ spillovers into those that are due to geographic proximity, to R\&D overlap, and to product market similarity.

An advantage of the index number formulation is that it overcomes the input endogeneity problem that is discussed in subsection 4.3 below by moving the inputs to the left hand side of the equation. In other words, they become part of the dependent variable.

An application to Canadian Productivity Growth. A problem that surfaces in much of the productivity literature - capacity utilization - is often not acknowledged. To illustrate, if capital is fixed, the production function approach assumes that the only way to change output during a downturn is to reduce labor usage. In other words the full plant is utilized but fewer workers operate it. In reality, however, some production lines can be shut down, which means that measured and utilized capital can differ. It also leads to a puzzling phenomenon; namely that measured TFP growth rates are pro-cyclical and technical efficiency declines during downturns. Gu and Wang (2013) propose a solution to this problem. They develop a method of adjusting TFP growth measures for changes in capacity utilization. In particular, they adjust percentage changes in capital in the

\footnotetext{
${ }^{6}$ One can relax these assumptions if revenue shares are replaced by expenditure shares. However, although typical data sets have data on revenues, they do not have data on total costs.
} 
Jorgenson-Griliches formulation to reflect percentage changes in capacity utilization. Moreover, they show that the utilization rate is equal to the ex post return to capital divided by the ex ante user cost of capital. They apply their adjustment to Canadian manufacturing data and find that it eliminates some, but not all, of the pro-cyclical bias.

\subsection{Functional Form}

Most of the empirical literature in IO has focused on the estimation of Cobb-Douglas production functions using firm- or plant-level panel data on output $(Y)$, a variable factor (labor $L$ ), and a quasi fixed factor (capital $K) ! 7$ This production function is,

$$
y_{i t}=\alpha_{L} \ell_{i t}+\alpha_{K} k_{i t}+\omega_{i t}+e_{i t}
$$

where $y_{i t}, \ell_{i t}$, and $k_{i t}$ are the logarithms of output, labor, and capital, respectively, of firm $i$ in period $t ; \omega_{i t}$ represents firm $i$ 's technical efficiency; and $e_{i t}$ is an additional error that is i.i.d. and uncorrelated with inputs (e.g., classical measurement error in output or transitory shocks that are realized after the firm's choice of inputs). Like index number formulations, the Cobb-Douglas relies on several restrictive assumptions. In particular, returns to scale (RTS), which equal $\alpha_{L}+\alpha_{K}$, are constant over time and across firms, and the elasticity of substitution between capital and labor is equal to one. Other functional forms relax these restrictions.

The CES production function $Y=\left[\delta L^{-\rho}+(1-\delta) K^{-\rho}\right]^{-v / \rho}$ (Arrow et al., 1961) retains the assumption that the elasticity of substitution is the same over time and across firms but relaxes the assumption that it equals one. A Taylor approximation to the CES around $\rho=0$ implies the following equation in logs (Kmenta, 1969):

$$
y_{i t}=\alpha_{L} \ell_{i t}+\alpha_{K} k_{i t}+\alpha_{L K}\left[\ell_{i t}-k_{i t}\right]^{2}+\omega_{i t}+e_{i t},
$$

with $\alpha_{L} \equiv v \delta, \alpha_{K} \equiv v(1-\delta)$, and $\alpha_{L K}=-\rho v \delta(1-\delta) / 2$. This specification has the advantage of being more general than the Cobb-Douglas but keeping the convenience of a linear-in-parameters regression model. Grieco, Li, and Zhang (2016) estimate a CES production function to study the problem of unobserved input price dispersion.

The translog production function (Christensen, Jorgenson, and Lau 1971),

$$
y_{i t}=\alpha_{L} \ell_{i t}+\alpha_{K} k_{i t}+\alpha_{L L} \ell_{i t}^{2}+\alpha_{K K} k_{i t}^{2}+\alpha_{L K} \ell_{i t} \times k_{i t}+\omega_{i t}+e_{i t},
$$

looks similar to the CES. However, the translog is more flexible, since it places no restrictions on input substitution patterns. In addition, unlike the other two functions, it relaxes the assumption that RTS are invariant over time and across firms. On the other hand, the CES formulation is more parsimonious, since the number of parameters does not increase with the number of inputs.

\footnotetext{
${ }^{7}$ More generally, $L$ and $K$ can be vectors of fixed and variable inputs.
} 
Grieco, Pinkse, and Slade (2016) use a translog to assess changes in economies of scale and other forms of efficiency that can be attributed to a merger.

\subsection{Dealing With Endogenous Inputs}

If unobserved productivity $\omega_{i t}$ is known to the firm when it chooses its inputs, inputs and unobserved productivity should be correlated and the OLS estimator of the production function parameters will be inconsistent (Marschak and Andrews, 1944). This is a fundamental problem in the estimation of production functions. 8

Two traditional approaches to dealing with this issue are the use of instrumental variables (IV) such as input prices, and the inclusion of firm fixed effects. With IV techniques, if firms in the sample operate in different input markets, we may observe significant cross-sectional variation in, for example, input prices. Unfortunately, however, this variation is apt to be correlated with unobserved productivity. The fixed-effect approach requires strong and implausible restrictions to generate consistent estimators: the time-variant component of the unobserved productivity should be unknown to the firm when it decides the amount of inputs and non-serially correlated (Griliches and Mairesse, 1999).

\subsubsection{Dynamic Panel Data Models}

Dynamic panel data methods have been used for the estimation of production functions under weaker restrictions than those in the fixed-effect estimator. Blundell and Bond (2000) consider a specification of unobserved productivity, $\omega_{i t}$, with three additive components, a firm fixed-effect, $\omega_{i}^{(1)}$, an aggregate time effect, $\omega_{t}^{(2)}$, and a firm-specific transitory shock that follows an $\operatorname{AR}(1)$ process, $\omega_{i t}^{(3)}$. The three components can be correlated with contemporaneous inputs. Given this error structure, we have the following transformations of the Cobb-Douglas production function $!^{9}$ The equation in levels (or quasi first differences),

$$
y_{i t}-\rho_{\omega} y_{i t-1}=\alpha_{L}\left[\ell_{i t}-\rho_{\omega} \ell_{i t-1}\right]+\alpha_{K}\left[k_{i t}-\rho_{\omega} k_{i t-1}\right]+\left(1-\rho_{\omega}\right) \omega_{i}^{(1)}+\omega_{t}^{*}+\xi_{i t},
$$

where $\rho_{\omega}$ and $\xi_{i t}$ are the parameter and innovation shock in the autoregressive process for $\omega_{i t}^{(3)}$. And the equation in first differences,

$$
\Delta y_{i t}-\rho_{\omega} \Delta y_{i t-1}=\alpha_{L}\left[\Delta \ell_{i t}-\rho_{\omega} \Delta \ell_{i t-1}\right]+\alpha_{K}\left[\Delta k_{i t}-\rho_{\omega} \Delta k_{i t-1}\right]+\Delta \omega_{t}^{*}+\Delta \xi_{i t} .
$$

With the equation in first differences, output and inputs in period $t-2$ and before are valid instruments since $\mathrm{E}\left(\Delta \xi_{i t} \mid y_{i t-2}, \ell_{i t-2}, k_{i t-2}\right)=0$. These moment conditions can be used to construct

\footnotetext{
${ }^{8}$ Other sources of endogeneity are the selection problem from the endogenous exit of firms from the industry, and measurement error in inputs (see Griliches and Mairesse, 1999).

${ }^{9}$ We describe the different estimation methods using the Cobb-Douglas production function. However, all the methods below can also be applied to estimate the other functional forms that are discussed in subsection 4.2
} 
a GMM estimator of the parameters $\left(\rho_{\omega}, \alpha_{L}, \alpha_{K}\right)$, which is the Arellano-Bond (1991) GMM estimator. However, it is known that this estimator suffers from a weak instruments problem when some of the endogenous explanatory variables $\left\{y_{i t-1}, \ell_{i t}, k_{i t}\right\}$ follow stochastic processes with substantial persistence (i.e., close to random walks). Unfortunately, this problem typically appears in the estimation of production functions.

To deal with this issue, Blundell and Bond (1998, 2000) propose a system-GMM estimator that combines the Arellano-Bond moment conditions with additional moment conditions for the equation in levels (8). Under the stationarity condition $\left|\rho_{\omega}\right|<1$, the error term $\left(1-\rho_{\omega}\right) \omega_{i}+\xi_{i t}$ is not correlated with the first difference of output and inputs at periods $t-1$ and before: $E\left(\left(1-\rho_{\omega}\right) \omega_{i}+\xi_{i t}\right.$ | $\left.\Delta y_{i t-1}, \Delta \ell_{i t-1}, \Delta k_{i t-1}\right)=0$. Importantly, these moment conditions have identification power even when the endogenous explanatory variables follow random walks. Blundell and Bond (2000) apply their System-GMM estimator to a sample of US manufacturing companies and find that the additional instruments yield more reasonable parameter estimates and pass specification tests.

This method, together with the control function approach that we describe below, is the most common approach to estimate production functions these days. To illustrate, Bloom, Schankerman, and Van Reenen (2015) use dynamic panel data methods to disentangle two countervailing R\&D spillover effects: a positive technology effect and a negative business stealing effect. They show that, due to these offsetting tendencies, the social returns to R\&D are significantly higher than the private returns.

\subsubsection{Olley-Pakes Models}

Olley and Pakes (OP, 1996) propose a control function method to deal with the endogeneity of inputs ${ }^{10}$ Their approach is based on a simultaneous equations model that consists of the production function in (5) and the firm's optimal decision rule for capital investment, $i_{i t}=f_{t}\left(k_{i t}, \omega_{i t}\right)$, where $i_{i t}$ represents investment at period $t$. There are three important assumptions on this investment function. First, input prices and other unobservable state variables affecting profits should not have cross-sectional variation. Therefore, the effect of these variables can be represented by the time subindex in the investment function, $f_{t}()$ 11 Second, the investment function should be strictly monotonic in the productivity shock $\omega_{i t}$. Third, the function is not stochastic. In particular, investment depends deterministically on the state variables. Under these conditions, an inverse function $\omega_{i t}=f_{t}^{-1}\left(k_{i t}, i_{i t}\right)$ exists and we can write:

$$
y_{i t}=\alpha_{L} \ell_{i t}+\phi_{t}\left(k_{i t}, i_{i t}\right)+e_{i t}
$$

\footnotetext{
${ }^{10}$ They also deal with the selection issue that arises when firms (nonrandomly) exit the data.

${ }^{11}$ If input prices are observable to the researcher and they have cross-sectional variation, they can be included in the investment equation such that it becomes $i_{i t}=f_{t}\left(k_{i t}, r_{i t}, \omega_{i t}\right)$, where $r_{i t}$ represents observable input prices. Then, the control function approach can be extended by including input prices in the set of control variables.
} 
where $\phi_{t}\left(k_{i t}, i_{i t}\right) \equiv \alpha_{K} k_{i t}+f_{t}^{-1}\left(k_{i t}, i_{i t}\right)$. Without a parametric assumption on the investment function $f_{t}$, equation 10 is a semiparametric partially linear model, and the parameter $\alpha_{L}$ and the functions $\phi_{t}($.$) can be estimated using semiparametric methods (Robinson, 1988).$

In a second step, the parameter for capital, $\alpha_{K}$, is estimated using moment restrictions based on two additional assumptions: unobserved productivity $\omega_{i t}$ follows a first order Markov process; and it takes one period for investment to become productive, i.e., time-to-built. For instance, if $\omega_{i t}$ follows an $\operatorname{AR}(1)$ process with parameter $\rho_{\omega}$, we have the equation

$$
\phi_{i t}-\rho_{\omega} \phi_{i t-1}=\alpha_{K}\left[k_{i t}-\rho_{\omega} k_{i t-1}\right]+\xi_{i t}
$$

where $\phi_{i t} \equiv \phi_{t}\left(k_{i t}, i_{i t}\right)$ has been estimated in the first step, and $\xi_{i t}$ is the innovation of the $\operatorname{AR}(1)$ process. Under the Markov and time-to-build assumptions, the unobservable $\xi_{i t}$ is orthogonal to $\phi_{i t-1}, k_{i t-1}$, and $k_{i t}$. The parameters $\rho_{\omega}$ and $\alpha_{K}$ can be estimated in equation (11) using (nonlinearly) restricted least squares 12

There have been many subsequent modifications of the basic OP model. For example, Levinsohn and Petrin (LP, 2003) propose an alternative control function method for applications where investment data presents significant censoring at zero investment. These censored observations cannot be used in the Olley-Pakes method because they do not satisfy the strict monotonicity condition between investment and productivity, and conditioning for investment does not control for unobserved productivity. To avoid this problem, Levinsohn and Petrin use the demand function for intermediate inputs, $m_{i t}=h_{t}\left(\omega_{i t}, k_{i t}\right)$, instead of the investment equation, and invert that function to obtain unobserved productivity.

Ackerberg, Caves, and Frazer (2015) identify an important identification issue in the control function approaches of OP and LP. In those models there is implicitly a labor demand equation which, like the demand for materials, should depend on the state variables, $\ell_{i t}=h_{t}\left(\omega_{i t}, k_{i t}\right)$. With the LP approach, this means that we can substitute the inverted materials demand equation into the labor demand equation to show that there is a deterministic relationship between employment, materials and capital in any cross-section $t$. This perfect collinearity means that it is not possible to identify the labor parameter $\alpha_{L}$ in the first step of the LP method. A similar argument applies to the OP method. Ackerberg, Caves, and Frazer (ACF) consider additional assumptions that can rescue the control function approach for production function estimation. In particular, they assume that labor is chosen before materials but after capital, which breaks the collinearity.

Note that the identification in ACF method fully relies on restrictions on the serial correlation of the productivity shock and on the existence quasi-fixed inputs. These are very similar to the restrictions in the dynamic panel data methods described above. The main difference between these methods is in the specification of the stochastic structure of the productivity shock.

\footnotetext{
${ }^{12}$ Wooldridge (2009) shows that OP and LP control function methods can be described as GMM methods and they can be implemented in a single step.
} 
These identification issues have renewed the interest in combining the production function with the restrictions provided by marginal conditions for flexible inputs (Doraszelski and Jaumandreu, 2013; and Gandhi, Navarro, and Rivers, 2016).

\subsubsection{Applications: Sources of Productivity Growth}

The estimation of production functions, and the corresponding measurement of productivity, has been applied in IO to study the contributions of different channels to the growth of productivity in an industry. Examples include exogenous technical change, reallocation of inputs among firms (including market entry and exit), adoption of new technologies, trade liberalization, improvements in product quality, and endogenous productivity growth related to investments in R\&D or exporting to foreign markets.

Olley and Pakes (1996) study the evolution of productivity in the US telecommunications industry after deregulation. They find that most of the increase in aggregate industry productivity was due to the reallocation of capital towards the more productive establishments, and a very small part comes from technical change.

Collard-Wexler and De Loecker (2014) investigate the sources of productivity growth in the US steel industry during 1963-2002. They find that the steel industry experienced a sharp increase in productivity during that period, and that this growth was mostly explained by the adoption of a new technology for producing steel - the minimill. The reallocation of inputs from plants using the old technology towards minimills accounts for a third of the increase in the industry's productivity. Interestingly, the authors find that the new technology had a second, indirect but quantitatively important, impact on productivity. The expansion of minimills increased competition in the industry, and this generated a substantial reallocation of inputs also within the firms maintaining the old technology.

De Loecker (2011) investigates the impact of trade liberalization on firm productivity. As most previous studies dealing with this question, the measure of output is deflated revenue and not output in physical units. De Locker proposes a novel approach to separately identify the contributions of (pure) productivity growth and prices. The empirical model combines a physical production function with a demand system for differentiated products to generate a structural revenue production function. De Loecker estimates his model using plant-product level data from Belgium and studies the impact of trade liberalization in the textile industry. He uses the reduction in quotas as an exogenous demand shifter for the identification of the structural parameters of the model. His empirical results show that distinguishing between revenue and physical output leads to a dramatic reduction in the estimate of the productivity increase from liberalization. In particular, his estimates imply that abolishing all quotas would lead to only a $2 \%$ change in productivity, in contrast to $8 \%$ when using measures of "productivity" based on deflated revenue. 
Finally, Doraszelski and Jaumandreu (2013) propose a model where the production function is Cobb-Douglas with capital, labor, and materials as inputs, but where total factor productivity follows an endogenous stochastic process that depends on the firm's investment in R\&D. More specifically, the process for productivity is $\omega_{i, t+1}=g\left(\omega_{i t}, r_{i t}\right)+\xi_{i, t+1}$, where $r_{i t}$ represents expenditures on $\mathrm{R} \& \mathrm{D}$, and $g$ is an unknown function to the researcher. They propose an estimator of the structural parameters of their model that combines first order conditions for flexible inputs (labor and materials) and the restrictions on the stochastic process for productivity (i.e., the innovation $\xi_{i, t+1}$ is orthogonal to variables from period $t$ and earlier). They estimate the model using a panel of Spanish manufacturing firms during 1990-1999. Their empirical results show that R\&D is a key determinant of the differences in productivity growth across firms.

\section{Dynamic Structural Models}

Competition in oligopoly markets involves important dynamic decisions. Firms' investments in capacity, inventories, product design, and market entry, have important implications for future profits. On the consumer demand side, storable and durable products, consumer switching costs, habit formation, and learning also introduce dynamic aspects in competition. During the last decades, the increasing availability of firm and consumer level longitudinal data and the advances in econometric methods and modeling techniques have facilitated the estimation of dynamic structural models of demand and supply in oligopoly industries.

\subsection{Firm Investment at the Extensive Margin}

Starting with the seminal work by Pakes (1986) and Rust (1987), models and methods for dynamic discrete choice structural models have been applied to study firm investment decisions at the extensive margin, e.g., market entry and exit, machine replacement, or adoption of a new technology ${ }^{13}$ Let $a_{i t} \in \mathcal{A}=\{0,1, \ldots, J\}$ be the discrete variable that represents the investment decision of firm $i$ at period $t$. The profit function is:

$$
\Pi_{i t}=p_{i t} f\left(a_{i t}, k_{i t}, \mathbf{z}_{i t} ; \theta_{y}\right)-c\left(a_{i t}, \mathbf{z}_{i t} ; \theta_{c}\right)+\varepsilon_{i t}\left(a_{i t}\right)
$$

$p_{i t}$ represents output price. The term $y_{i t}=f\left(a_{i t}, k_{i t}, \mathbf{z}_{i t} ; \theta_{y}\right)$ is a production function that depends on investment, $a_{i t}$, predetermined installed capital, $k_{i t}$, exogenous variables, $\mathbf{z}_{i t}$, and the structural parameters $\theta_{y}$. The term $c\left(a_{i t}, \mathbf{z}_{i t} ; \theta_{c}\right)$ captures the cost of investment, and $\theta_{c}$ is a vector of structural parameters. The vector of variables $\varepsilon_{i t}=\left\{\varepsilon_{i t}(a): a \in \mathcal{A}\right\}$ represents a component of the investment cost that is unobservable to the researcher. The capital stock $k_{i t}$ depreciates exogenously and increases when new investments are made according to a standard capital accumulation rule.

\footnotetext{
${ }^{13}$ In this section, we review applications that abstract from dynamic oligopoly competition or assume explicitly that firms operate in either competitive or monopolistic markets.
} 
Every period $t$, the manager observes the state variables $k_{i t}, p_{i t}, \mathbf{z}_{i t}$, and $\varepsilon_{i t}$ and decides its investment to maximize expected and discounted profits $\mathbb{E}_{t}\left(\sum_{j=0}^{\infty} \delta^{j} \Pi_{i, t+j}\right)$, where $\delta \in(0,1)$ is the discount factor. The solution of the dynamic programming problem implies an optimal decision rule for investment as a function of state variables and structural parameters. This decision rule and the distribution of the unobservables imply a probability for the observed path of output and investment of a firm. Rust (1987) proposed the Nested Fixed Point algorithm (NFXP) for the computation of the maximum likelihood estimator of the parameters of this model. Hotz and Miller (1993) propose a two-step Conditional Choice Probabilities (CCP) estimator that avoids computing a solution of the dynamic programming problem. Aguirregabiria and Mira (2002) propose the Nested Pseudo Likelihood algorithm (NPL) that is a recursive extension of the CCP method that returns the maximum likelihood estimates at a lower computing time than NFXP.

Das (1992) studies the decision to operate, hold idle, or retire a kiln by plants in the U.S. cement industry. Kennet (1994) analyzes airlines' replacement decisions of aircraft engines and identifies significant changes in the decision rule after the deregulation of the US airline industry in 1978. Roberts and Tybout (1997) investigates why the decision to export by Colombian manufacturing plants is very persistent over time, and disentangle the contribution of sunk entry costs, exporting experience, and serially correlated unobserved heterogeneity. Kasahara (2009) studies the effect of import tariffs on capital investment decisions by Chilean manufacturing plants. He shows that the announcement that the tariff would be temporary exacerbated its negative impact on firms' investment. Rota (2004) and Aguirregabiria and Alonso-Borrego (2014) estimate dynamic discrete choice models of labor demand and use them to measure the magnitude of labor adjustment costs and the effects of labor market reforms. Holmes (2011) studies the geographic expansion by WalMart stores. He estimates a dynamic model of entry and store location that incorporates economies of density and cannibalization between stores. Holmes finds that Wal-Mart obtains large savings in distribution costs by having a dense store network.

\subsection{Dynamic Pricing}

Sales promotions account for a very substantial part of price changes and of the cross-sectional price dispersion of retail products (see Hosken and Reiffen, 2004, Nakamura and Steinsson, 2008, or Midrigan, 2011). Understanding the determinants of temporary sales is important to understand price stickiness, price dispersion, and firms' market power and competition. Varian (1980) presents a model of price competition in an homogeneous product market with two types of consumers according to their information about prices. The equilibrium of the model is characterized by a Ushape density function for prices. The price charged by a store changes randomly over time between a "low" and a "high" price. Though Varian's model can explain some important empirical features in the cross-section and time series of prices in retail markets, it cannot explain the duration 
dependence of sales promotions that have been reported in empirical studies. Several studies have proposed and estimated dynamic structural models of retail pricing that can explain price dispersion, sales promotions and their state dependence. These studies provide also estimates of the magnitude and structure of firms' price adjustments costs.

Slade (1998) proposes a model where the demand for a product in a store depends on a stock of goodwill that accumulates over time when the store charges low prices, and erodes when the price is high. The model incorporates also menu costs of changing prices. The optimal pricing policy consists of a cycle between a low price (or sales promotion) and a high price. Slade estimates this model using weekly scanner data of prices and quantities of saltine crackers in four supermarket chains. The estimated model fits well the join dynamics of prices and quantities. Her estimates of the cost of adjusting prices are approximately $4 \%$ of revenue.

Aguirregabiria (1999) studies the relationship between inventories and prices in supermarkets. Retailers have lump-sum costs of placing orders, menu costs of changing prices, face substantial demand uncertainty, and experience stockouts. Aguirregabiria proposes a model of price and inventory decisions that incorporates these features. In the optimal decision rule of this model, inventories follow an $(\mathrm{S}, \mathrm{s})$ cycle. Optimal prices depend negatively on the level of inventory and have a "high-low" cyclical pattern. Aguirregabiria estimates this model using data on inventories, prices, and sales from the warehouse of a supermarket chain. The estimated model shows that almost $50 \%$ of sales promotions are associated to the dynamics of inventories.

Pesendorfer (2002) proposes a model of demand for a storable product and shows that the dynamics of consumer inventory can explain sales promotions. The equilibrium of the model predicts that the probability that a store has a sale increases with the duration since the last sale both in that store and in other stores. Using supermarket scanner data for ketchup products, Pesendorfer shows that sales promotions have duration dependences that are consistent with the model.

Kano (2013) studies how dynamic price competition in oligopoly markets can be an important source of price inertia even when menu costs are small. Strategic complementarity in price competition, together with menu costs, implies that firms may decide not to respond to firm-idiosyncratic shocks because they know that their competitors will maintain their prices constant. Kano estimates a dynamic pricing model that incorporates these strategic interactions and finds that they account for a substantial part of price rigidity. A model of monopolistic competition that ignores strategic interactions among firms can spuriously overestimate menu costs.

\subsection{Dynamic Demand for Differentiated Products}

Many products are storable and consumers can buy them for future consumption. Static demand models ignore these dynamics and they can generate substantial biases and misinterpretations of consumer demand. Erdem, Imai and Keane (2003) and Hendel and Nevo (2006) propose dynamic 
discrete choice models of the demand for storable differentiated products and estimate these models using consumer level scanner data.

Every period $t$, the consumer decides whether purchase one of $J$ brands of a product, and the number of units (or size) $q$. Let $d_{i t} \in\{0,1, \ldots, J\}$ and $q_{i t} \in\{1,2, \ldots, Q\}$ represent the brand choice and quantity choice of consumer $i$ at time $t$, respectively. The consumer also decides how much to consume of each brand, that is represented by the $J$ dimensional vector $\mathbf{c}_{i t}$. Given choice $\left\{d_{i t}=j\right.$, $\left.q_{i t}=q, \mathbf{c}_{i t}=\mathbf{c}\right\}$, the per period utility of consumer $i$ is:

$$
U_{i t}(j, q, \mathbf{c})=u_{i t}(\mathbf{c})-C_{i t}\left(\mathbf{k}_{i t}\right)+x_{j q t} \beta_{i}-\alpha_{i} p_{j q t}+\xi_{j q t}+\varepsilon_{i j q t}
$$

$u_{i t}(\mathbf{c})$ is the utility from consumption; $C_{i t}\left(\mathbf{k}_{i t}\right)$ is the cost of holding inventories, where $\mathbf{k}_{i t}$ is the $J$ dimensional vector of inventories by brand; and the term $x_{j q t} \beta_{i}-\alpha_{i} p_{j q t}+\xi_{j q t}+\varepsilon_{i j q t}$ represents the utility from purchasing $q$ units of brand $j$. The consumer makes purchasing and consumption decisions to maximize her expected and discounted intertemporal utility.

To make this dynamic demand model estimable, researchers must deal with the curse of dimensionality due to the very large number of state variables. For instance, Hendel and Nevo (2006) assume that there is product differentiation at the moment of purchase but not for consumption and inventory holding. This implies that vectors $\mathbf{c}_{i t}$ and $\mathbf{k}_{i t}$ becomes scalars, the brand choice is a static decision, and all the dynamics is in the quantity choice $q$.

The empirical results in Hendel and Nevo (2006) and Erdem, Imai, and Keane (2003) show that a static demand model that neglects consumer stockpiling behavior generates very substantial biases. Hendel and Nevo show that a static model overestimates own-price elasticities by 30 percent, and underestimates cross-price elasticities by up to a factor of five.

Gowrisankaran and Rysman (2012) propose and estimate a dynamic structural model of the demand for a differentiated durable product. Every period $t$, the consumer decides whether to purchase one of the $J_{t}$ varieties of a durable good (digital camcorders), or not to make any purchase and consume the variety she owns from her last previous purchase. Gowrisankaran and Rysman estimate this model using aggregate market level data. 14 Their estimation method nests the solution of the dynamic programming problem inside an inner loop with the GMM method proposed by Berry, Levinsohn and Pakes (1995) in the static model.

Schiraldi (2011) estimates a dynamic structural model of consumer demand for new and used automobiles. The model accounts for the second hand market, depreciation of automobiles, and transaction costs of replacement. The model implies that transactions costs can be identified from the difference between the share of consumers choosing to hold a given car type (not replace) and

\footnotetext{
${ }^{14}$ With aggregate data we do not observe the purchase history of each consumer, and this makes the identification of dynamic models significantly more difficult. There are not studies yet deriving general conditions for the identification of dynamic demand of differentiated products with market level data.
} 
the share of consumers purchasing the same car type that period. Schiraldi estimates his model using data from the Italian automobile market, and evaluates the impact of scrappage subsidies.

\subsection{Dynamic Games of Oligopoly Competition}

Firms compete not only in prices or quantities but also in other dimensions such as market entry, capacity, quality, advertising, R\&D and innovation, or product design. Since the seminal work by Bresnahan and Reiss (1990, 1991) and Berry (1992), empirical IO has experienced a substantial growth in the estimation of discrete choice games of oligopoly competition. This class of models has been applied to study market entry but also other forms of competition at the extensive margin such as product design (Mazzeo, 2002, Draganska, Mazzeo, and Seim, 2009), store location (Seim, 2006), release date of a movie (Einav, 2010), form of pricing (Ellickson and Misra, 2008), or provision of customer services (Rennhoff and Owens, 2012), among others.

During the last decade, empirical discrete choice games have been extended to incorporate dynamics. Ericson and Pakes (1995) provide a flexible framework for dynamic games of oligopoly competition that has become influential in IO. Aguirregabiria and Mira (2007) propose an estimable dynamic game based on Ericson-Pakes framework. Time is discrete and the game is played by $N$ firms. The decision variable of firm $i$ at period $t$ is $a_{i t} \in \mathcal{A}=\{0,1, \ldots, J\}$. This action is taken to maximize the expected and discounted flow of profits in the market. The profit function is:

$$
\Pi_{i t}=\pi_{i}\left(a_{i t}, \boldsymbol{a}_{-i t}, \mathbf{x}_{i t}\right)+\varepsilon_{i t}\left(a_{i t}\right)
$$

where $\boldsymbol{a}_{-i t}$ is the vector with the actions of the other firms, $\mathbf{x}_{i t}$ is a vector of state variables which are common knowledge to all the firms, and $\varepsilon_{i t} \equiv\left\{\varepsilon_{i t}(a): a \in \mathcal{A}\right\}$ is a vector of shocks that are private information of firm $i$ and i.i.d. across firms and over time with CDF $G$. The vector of state variables $\mathbf{x}_{i t}$ includes exogenous state variables (e.g., exogenous market characteristics affecting demand and costs), and endogenous state variables. The nature of the endogenous variables depends on the specific application. For instance, in a game of market entry the firm's incumbency status at previous period, $a_{i, t-1}$, is a state variable because it determines whether the firm has to pay an entry cost to be active in the market.

Following Maskin and Tirole (1988a), most of the recent literature in IO studying industry dynamics uses the solution concept of Markov Perfect Equilibrium (MPE). The key assumption in this equilibrium concept is that players' strategies are functions of only payoff-relevant state variables. In this model, the vector of payoff-relevant state variables for firm $i$ is $\left(\mathbf{x}_{t}, \varepsilon_{i t}\right)$, where $\mathbf{x}_{t}$ is the vector of the common knowledge state variables from all the firms. A MPE is an N-tuple of strategy functions, $\left\{\alpha_{i}\left(\mathbf{x}_{t}, \varepsilon_{i t}\right)\right\}_{i \in\{1,2, \ldots, N\}}$, such that a firm's strategy maximizes its value taking as given the strategies of the other firms.

In most applications of dynamic games in empirical IO, the researcher observes firms' actions 
and state variables for a sample of $M$ markets over $T$ periods of time. The dimensionality of the state space, and especially the multiplicity of equilibria, make the standard maximum likelihood nested fixed point algorithm computationally unfeasible in actual applications of dynamic games. As a result, researchers have turned to alternative methods based on the ideas of Hotz and Miller (1993) and Aguirregabiria and Mira (2002), i.e., estimation methods based on conditional choice probabilities (CCP). Two-step CCP methods for the estimation of dynamic games have been proposed by Aguirregabiria and Mira (2007), Bajari, Benkard, and Levin (2007), and Pesendorfer and Schmidt-Dengler (2008). Under the assumptions of single equilibrium in the data (i.e., sample observations at the different markets have been generated from the same MPE) and no unobserved common-knowledge variables, the structural parameters of the model can be estimated using a twostep approach. The assumption of no unobserved common-knowledge variables can be relaxed by using recursive extensions of these two-step methods (see Aguirregabiria and Mira, 2007, and Arcidiacono and Miller, 2011), or by applying nonparametric finite mixture models in the estimation of CCPs at the first step (Kasahara and Shimotsu, 2008, Igami and Yang, 2016).

(a) Entry and exit in retail markets. Suzuki (2013) examines the impact of land use regulations on entry costs, fixed costs, and market structure in the hotel industry. He estimates a dynamic game of entry-exit of mid-scale hotels in Texas that incorporates measures of land use regulation into the cost functions of hotels. The estimated model shows that imposing stringent regulation has substantial effects on market structure and hotel profits.

Dunne et al. (2013) estimate a dynamic game of entry and exit in the retail industries of dentists and chiropractors in US, and use the estimated model to evaluate the effects on market structure of subsidies for entry in small geographic markets. The authors compare the effects of this subsidy with those of a counterfactual subsidy of fixed costs, and they find that entry costs subsidies are more effective for the same present value of the subsidy.

(b) Investment in capacity in manufacturing industries. Ryan (2012) studies the effects of the 1990 Amendments to the Clean Air Act on the US cement industry. He estimates a dynamic game of market entry, exit, and capacity investment before and after the policy change. The estimated model shows that the new regulation had negligible effects on variable production costs but it increased significantly the sunk cost of opening a new cement plant. A static analysis, that ignores the effects of the policy on firms' entry-exit decisions, would conclude that the regulation had negligible effects on firms profits and consumer welfare. In contrast, the dynamic analysis shows that the increase in sunk entry costs caused a reduction in the number of plants that in turn implied higher markups and a decline in consumer welfare.

Collard-Wexler (2013) estimates a dynamic game of investment and entry in the US concrete industry and studies the effect of demand uncertainty on investment. Eliminating the short-term volatility of demand implies a $39 \%$ increase in the number of plants in the industry, reduces entry 
and exit by $25 \%$, and increases very significantly the market share of larger plants. Kalouptsidi (2014) studies the impact of time-to-build and demand uncertainty in the bulk shipping industry.

(c) Endogenous product design. Sweeting (2013) estimates a dynamic game of the US commercial radio industry. The model endogenizes the choice of format (genre) by radio stations, and estimates product repositioning costs. The estimated model is used to evaluate the effects of a new legislation that makes music stations pay fees for musical performance rights. Sweeting finds that these fees have a moderate, but still significant, long-run effect on the number of music stations.

Aguirregabiria and Ho (2012) propose and estimate a dynamic game of network competition between airlines that endogenizes airlines' routes. The authors study the contribution of demand, costs, and strategic factors to explain the adoption of hub-and-spoke networks by some companies in the US airline industry. The estimated model shows that the main effect is that the sunk cost of entry in a route declines importantly with the number of cities that the airline connects to from the origin and destination airports of the route. Entry deterrence, as defined in Hendricks, Piccione, and Tan (1997), is the second most important motive to adopt a hub-and-spoke network.

(d) Innovation in oligopoly industries. Goettler and Gordon (2011) study competition between Intel and AMD in the PC microchip industry. In their model, firms compete in prices and in product innovations. Price competition is dynamic because PCs are durable goods. The estimated model shows that removing competition from AMD implies an increase in consumer surplus but lower innovation.

Igami (2017) estimates a dynamic oligopoly model of product innovation in the hard disk industry, and studies the small propensity to innovate by incumbents relative to new entrants $(57 \%$ gap). The model includes cannibalization between existing and new products, preemptive motives, and differences in costs as potential factors that can explain differential propensities to innovate by incumbents and new entrants. The empirical results show that, despite strong preemptive motives and cost advantages, cannibalization makes incumbents reluctant to innovate.

Cannibalization and preemption in the Canadian fast-food industry. Igami and Yang (2016) study the evolution of the network of stores of hamburger retail chains in Canada. The dataset consists of the geographic location and the opening and closing dates of restaurants from the five largest chains in the seven major Canadian cities during the period 1970-2005. Igami and Yang estimate a dynamic oligopoly game of market entry and exit that allows for time-invariant unobserved market heterogeneity. They find substantial degree of cannibalization between stores of the same chain. Preemption motives are also relevant to explain McDonald's entry behavior. 


\section{$6 \quad$ Interfirm Contracting}

Some transactions take place within firms (vertical integration) and some occur at arm's length (spot markets). However, many others are governed by long term contracts, which are intermediate forms of organization that attempt to remedy the problems that are associated with the two extremes. In this section, we review the empirical evidence on contracting between firms. In particular, we look at empirical work based on agency considerations (Holmstrom, 1979, 1982), transaction cost motives (Williamson, 1975, 1979), and property rights models (Grossman and Hart, 1986; Hart and Moore, 1990). Compared to the other sections in this article, there are two reasons why the research that is discussed here is somewhat different: first, it tends to be reduced form; and second, it is usually designed to test the predictions of specific theoretical models.

We consider a principal - a manufacturer or franchisor - and an agent - a supplier or retailer — who sign a contract. With an agency model, both principal and agent must exert effort; for example, the principal's effort can influence the quality of the brand or trademark whereas the agent's effort can promote it. If efforts are unobservable, we have a double sided moral hazard problem. With double sided moral hazard, contracts can be used to allocate effort incentives between principal and agent. In addition, the parties can have different risk attitudes and contracts can also allocate risk bearing.

With agency models, contracts are complete. However, both transaction cost (TC) and property rights $(\mathrm{PR})$ theories emphasize incomplete contracts - ones that do not specify the actions that will be taken under all possible contingencies. Incomplete contracts cause problems when assets are specific, that is, when their value inside the relationship is greater than outside. TC and PR models differ, however, in important ways. The first emphasizes ex post renegotiation, haggling, and opportunistic behavior when both parties attempt to capture the rent that was created by specific investments. The second, in contrast, emphasizes ex ante investment and how the allocation of property or residual control rights influences investment decisions by changing the status quo in the ex post bargaining game.

Although contracts can take many forms, linear share contracts are common in many settings. Those contracts take the form of $\alpha q+f$, where $q$ is output or revenue, $\alpha$ is the share of output that the agent receives, and $f$ is a fixed fee (wage) that the agent pays (is paid). Table 1 classifies share contracts. In particular, the two extremes, $\alpha=0$ and $\alpha=1$, correspond to vertical integration and spot market transaction. When $\alpha$ is between zero and one, we have a share contract that involves risk sharing and provides intermediate incentives to both parties. If we assume that the principal is less risk averse than the agent, the table illustrates the moral hazard tradeoff between providing

agents with insurance against risk and giving them incentives to exert effort. It also illustrates a second tradeoff between providing incentives to the principal and to the agent. 
Although property rights theories usually consider the two extremes of principal or agent ownership, if one interprets the share parameter as the probability of agent ownership, those models can also be seen in terms of table 1. In particular, there is a tradeoff between providing investment incentives to the principal or to the agent, with $\alpha=0$ corresponding to vertical integration (principal ownership) and $\alpha=1$ to market transaction (agent ownership).

\subsection{Empirical Analysis of Agency Models}

Many empirical tests of agency theories analyze share contracts, which are used in numerous settings including movie distribution (Mortimer, 2008, Gil and Lafontaine, 2012), shopping malls (Gould, Pashigan, and Prendergast, 2005), airlines (Forbes and Lederman, 2013), joint ventures (Bai, Tao, and $\mathrm{Wu}, 2004$ ), and licensing agreements (Anand and Khanna, 2000). We begin by looking at applications that assess share contracts in franchising. The findings from that setting, however, are mirrored in many others.

Agency models yield many predictions that can be taken to the data. In particular, compared to company ownership, we expect to see more franchising (higher $\alpha$ ) when the market is riskier, the agent's effort is more important relative to the principal's, and monitoring the agent is easier (since direct monitoring is a substitute for incentive provision). Moreover, some studies assess the propensity to franchise outlets, a 0/1 decision (Brickley and Dark, 1987), others the fraction of outlets franchised (Norton, 1988), the terms of the contract, $\alpha$ and $f$ (Lafontaine, 1992; Brickley, 2002), and the behavior of those terms over time (Lafontaine and Shaw, 1999). The conclusions from these and other tests from many industries are summarized in (Lafontaine and Slade, 2007), who note that the prediction that the agent (principal) will be given stronger incentives when the agent's (principal's) effort is a more important determinant of profitability is strongly supported. Furthermore, the predictions concerning monitoring are also confirmed by the data. ${ }^{15}$ In sharp contrast, the findings concerning risk are not supportive of the risk/insurance tradeoff. We return to this issue later.

An interesting variant of the agency model is developed in Bitler, Moskowitz, and VissingJorgenson (2005) who assess the share of capital that an entrepreneur (the agent) must sell to outside investors (the principals) who are concerned with moral hazard. In their data, they observe agent effort and wealth as well as capital and labor inputs, and they model the simultaneous choice of effort and conventional inputs, conditional on wealth. They conclude that entrepreneurial equity shares decline with risk and increase with wealth, which is consistent with the risk/insurance tradeoff.

\section{An Application from Vancouver}

\footnotetext{
${ }^{15}$ Conclusions concerning monitoring seem contradictory at first. However, Lafontaine and Slade (1996) develop a model with two sorts of monitoring that explains the findings of others well.
} 
The studies discussed thus far are concerned with an agent who performs a single task. However, in reality most agents must perform multiple tasks, a situation that is modeled in Holmstrom and Milgrom (1991, 1994), who show that the characteristics of one task can affect the optimal payment scheme for another. Slade (1996) tests these predictions using data on share contracts signed by gasoline service stations (the agents) and vertically integrated oil companies (the principals) in Vancouver. In this setting, each agent performs two tasks: selling gasoline - the primary task and either repairing autos or working in a convenience store - the secondary tasks. Moreover, she argues that, compared to repairs, which are preformed in the backcourt, convenience store sales, which can involve a common cash register, are more complementary with gasoline sales, where complementarity is defined in terms of cross-price elasticities, covariation in uncertainty, and cross partials of the cost of effort function. In this industry, principal and agent sign a contract that is based solely on gasoline sales. However, the power of the incentives in those contracts differs across contracts types. Slade asks if the characteristics of the secondary task can explain the differences in incentives for the primary and concludes that the theoretical prediction that agents should be given lower powered incentives when the activities that they perform are more complementary is supported.

\subsection{Empirical Analysis of Transaction Cost Models}

Transaction cost arguments, which are less theoretical and more intuitive than the other two, also yield a rich set of predictions that can be taken to data. Moreover, whereas empirical tests of agency models are most often concerned with manufacturer retailer relationships, transaction cost and property rights studies usually examine procurement. For example, in an early study, Masten (1984) looks at how the characteristics of an input that a firm uses can explain the make (vertical integration) or buy (contract out) decision. The characteristics that he focuses on are specificity, complexity, and the importance of co-location, and he argues that an increase in any of those characteristics favors internal organization of a transaction. Using data on input procurement by aerospace firms, he finds evidence that favors for all three. Furthermore, as summarized in Lafontaine and Slade (2007) many other researchers have tested those predictions and have also found empirical support.

Contract duration is another characteristic that has often been subject to scrutiny. Indeed, researchers argue that contracts will be longer when firms have made more specific investments, since the need to protect those investments is greater. Joskow $(1985,1987)$ was perhaps the first to test this prediction. He used data on the relationship between coal suppliers and electric utilities and found support for the notion that, when the generation plant is located at the mine mouth, and thus the investment is more specific, contracts are of longer duration. Since that time many other researchers have assessed the relationship between specificity and duration and have found 
evidence of a positive relationship between the two, results that are summarized in Lafontaine and Slade (2012).

\subsection{Empirical Analysis of Property Rights Models}

Given that both transaction cost and property rights models focus on incomplete contracts and specific investments, many researchers do not make a clear distinction between the two. However, some recent studies provide more clear-cut tests of property rights theories. We focus our discussion here on a few studies of ownership and control rights ${ }^{16}$

Two studies of alliances between firms, Lerner and Merges (1998), who assess technology alliances, and Elfenbein and Lerner (2003) who study internet portal alliances, examine the allocation of ownership and control. Both studies focus on two predictions: i) ownership of critical elements should be assigned to the party whose effort is more important to the success of the agreement and ii) the allocation of control rights should be sensitive to the relative bargaining power of the parties. The studies confirm both theoretical predictions.

An interesting variant is provided by Acemoglu, Aghion, Griffith, and Zilibotti (2010), who assess technology intensity rather than specificity. Like the model of Grossman and Hart (1986), their model predicts that technology intensities of suppliers and producers should affect the likelihood of vertical integration in opposite directions. Furthermore, using data on UK manufacturing plants, they provide evidence that supports that hypothesis. Moreover, they find that the effect is larger when the upstream firm is an important supplier.

Although the theories are very different, much research on property rights has a distinct agency flavor. For example, Baker and Hubbard (2004) investigate how the relationships between trucking firms and truck drivers are affected by contractual incompleteness and how those relationships change with the introduction of a new technology. In particular, they note that there is a tradeoff between having residual control rights (higher powered incentives) assigned to the driver, which leads to better maintenance of the truck, or to the company, which leads to better utilization of the fleet as a whole and less rent dissipation. Moreover, they find that the new technology, onboard computers, mitigated contractual incompleteness (lowered monitoring costs) and led to a fall in driver ownership.

Finally, the classification in table 1 indicates that, if one interprets important effort as important decisions/investments, then the many studies of the relative importance of agent (principal) effort that are discussed in section 6.1 can be seen as lending support to property rights theories as well. In that sense, property rights predictions can be seen as closer to agency than to transaction cost predictions.

\footnotetext{
${ }^{16}$ Table 3 in Lafontaine and Slade (2012) summarizes the allocation of control rights in many different settings.
} 


\subsection{Unobserved Heterogeneity}

Most studies in the contracting literature treat principal, agent, and market characteristics as exogenous. However, a combination of unobserved heterogeneity and endogenous matching of agents to contracts, which is common in contractual settings, will lead to selection bias. In particular, the problem occurs when some characteristics are not observed and are omitted or when imperfect proxies are used. Although selection issues surface in many contractual environments, we illustrate with an agency model.

Agency theories predict that, all else equal, there should be a negative relationship between the risk that agents bear and the power of their incentives. The problem is that all else is very rarely equal. In particular, most empirical studies either ignore risk aversion, which is difficult to measure, or use an imperfect proxy such as wealth. Unfortunately, both practices can lead to biased coefficients. Furthermore, it is possible that the coefficients of risk in contract choice equations will have perverse signs. For example, many researchers find that higher risk is associated with higher, not lower powered incentives, which is often described as a puzzle ${ }^{17}$ However, this empirical regularity could be explained if agents with high (low) risk tolerance choose riskier (less risky) markets and riskier (less risky) contracts, which would lead to a positive correlation between risk bearing and incentives in the data.

A number of solutions have been proposed as a remedy for the unobserved heterogeneity problem. For example, one could use panel data in which agents sign more than one contract. The problem with that solution is that agents rarely change markets (and therefore the riskiness of their market). Furthermore, the terms of contracts that are offered by individual franchisors show remarkably little temporal variation Lafontaine and Shaw (1999).

In the context of sharecropping, Ackerberg and Botticini (2002) propose an instrumental variable solution in a reduced form setting. They suggest estimating a matching equation that includes instruments that affect the matching process between principals and agents but do not influence the terms of the contract. In their agricultural setting, the choice is between sharecropping and fixed rent contracts, and they argue that one can exploit cross regional variation in contract terms to create geographic instruments. Unfortunately, in the interfirm context, this is often not feasible. For example, at any point in time, McDonald's offers the same franchise contract to all of its franchisees.

In the context of health insurance, Handel (2013) proposes a structural remedy and applies it to the choice of insurance plan. In his model, agents have CARA utilities and the coefficient of absolute risk aversion is modeled as a random coefficient that is a function of family demographics. He uses forecasts of out of pocket expenses, the risky variable, to create a family and health plan specific ex ante distribution of risk and creates an expected utility function by integrating over

\footnotetext{
${ }^{17}$ See the summary findings and theories that might explain those findings in Lafontaine and Slade (2007).
} 
those distributions. Finally, he assumes that each family chooses the plan that maximizes its utility. However, he studies the role of adverse selection and does not evaluate the risk insurance tradeoff. Nevertheless, the techniques that he develops could be used in an interfirm moral hazard setting.

Unfortunately, much more research is needed in the interfirm contracting area before one can determine if endogenous matching can explain the empirical risk/incentive puzzle that surfaces in so many applied studies.

\subsection{Structural Contracting Models}

The research that we have discussed in this section so far is mostly reduced form. However, there is a growing structural contracting literature, and the two sorts of models differ in important ways. First, whereas agency models are often cast in a competitive downstream environment with principals making take it or leave it offers, structural models usually consider strategic behavior in both up and downstream markets. Second, whereas the former emphasize the alignment of effort incentives between principal and agent or investment incentives across firms in a vertical chain, the inefficiency that the latter emphasize is the double marginalization that results when both links in the chain have market power. Finally, in contrast to reduced form models that cannot be used for welfare analysis, welfare calculations are often the primary objective of structural modeling.

A generic structural contracting model has three layers: an upstream market, a downstream market, and an interface between the two (the contract), and one must specify the structure of all three. For example, one might assume that both up and downstream competition is Bertrand Nash, whereas the contract might be determined in a Nash bargaining game. As with any structural model, the conclusions that are reached depend critically on the accuracy of the assumptions that are made, which should be tailored to fit the markets and institutions that are studied.

Structural models can be divided into two classes that depend on whether the researcher has data on the contracts. We discuss studies that make use of contracting data before turning to the second class. Mortimer (2008) is perhaps closest in spirit to the incentives literature. She specifies a structural model of the video rental market and contrasts linear pricing with share contracts. Film distributors are modeled as monopolists over single films whereas downstream retailers behave in a Cournot fashion. Finally, distributors offer linear pricing or share contracts, and retailers choose a contract and an inventory of films. She finds that share contracts align incentives between distributor and retailer, increase profits for both, and lead to higher consumer welfare. Crawford and Yurukolu (2012), who study interactions between content conglomerates and cable television channels, and Gowrisankaran, Nevo, and Town (2015), who assess competition between hospitals and managed care organizations, take a different approach to the interface. In particular, they use a bargaining model that is due to Horn and Wolinsky (1988), which nests a Nash bargaining 
solution within a Nash equilibrium and includes take-it-or-leave-it offers as a special case. Both find that bargaining restrains downstream prices and increases consumer welfare.

Studies that do not have data on contracts are more closely related to the research on demand and collusion that is discussed in subsections 2 and 3 than to the incentive contracting literature. In particular, it is often assumed that competition up and downstream is differentiated products Bertrand, and total (i.e., up plus downstream) marginal costs are recovered as those that reconcile the equilibrium assumptions. However, there is a second set of unobserved parameters - those of the contract - that affect marginal costs. Usually a menu of contracting models (e.g., linear

pricing and two part tariffs) is estimated and non-nested hypothesis tests are used to discriminate among them. Finally, the welfare implications of vertical restraints are often evaluated. Examples in this class include Brenkers and Verboven (2006), Berto Villas-Boas (2007), and Bonnet and Dubois (2010).

\section{Auctions}

Auctions are common mechanisms for selling goods and services such as agricultural products (e.g., fish, livestock), natural resources (e.g., timber, oil and gas drilling rights), government contracts, money in interbank markets, treasury bonds, electricity, or art work. More recently, internet auctions (e.g., eBay) have become a popular way of selling a diverse range of products.

Auctions can be modelled as games of incomplete information. A seller (or a buyer, in the case of a procurement auction) is interested in selling an object. The seller faces a number of potential buyers or bidders, and she does not know their valuations of the object. A bidder knows his own valuation of the object but not other bidders' values. Each bidder submits a bid to maximize his expected payoff. The rules of the auction (e.g., first price sealed bids, second price) determines who gets the object and the price he should pay. These rules, the conditions on bidders' information, and the correlation between their valuations (e.g., independent private values, common values) are important features that determine the predictions of the model.

Consider the auction of a single object with $N$ bidders indexed by $i \in\{1,2, \ldots, N\}$. Bidder $i$ 's valuation for the object is $u_{i}=U\left(v_{i}, c\right)$ where $U(.,$.$) is an increasing function in both arguments;$ $v_{i}$ represents a bidder's private signal; and $c$ is a common value that affects the valuations of all the bidders. It is assumed that the value of the vector $\left(v_{1}, v_{2}, \ldots, v_{n}, c\right)$ is a random draw from the joint cumulative distribution function $\mathbf{F}\left(v_{1}, v_{2}, \ldots, v_{n}, c\right)$ that is continuously differentiable and has compact support $[\underline{v}, \bar{v}]^{n} \times[\underline{c}, \bar{c}]$. Each bidder knows her own private value $v_{i}$ and the functions $U$ and F, but she does not know the other bidders' private values. Depending on the model, she may or may not know the common component $c$. The game is said to be symmetric if bidders are identical ex ante, i.e., if the distribution $\mathbf{F}$ is exchangeable in its first $N$ arguments.

Each bidder decides her bid, $b_{i}$, to maximize her expect payoff. Most of the empirical literature 
has focused on first-price auctions: the winner is the highest bidder (provided it is higher than the seller's reservation price) and she pays her bid. Under this rule, the expected payoff is:

$$
\pi_{i}^{e}\left(b_{i}\right)=\mathbb{E}\left(1\left\{b_{i}>b_{j} \forall j \neq i\right\} \quad\left[U\left(v_{i}, c\right)-b_{i}\right]\right)
$$

where $1\{$.$\} is the indicator function. This literature assumes that bids come from a Bayesian$ Nash equilibrium (BNE). This BNE is described as a vector of $N$ strategy functions $\left\{s_{i}\left(v_{i}\right): i=\right.$ $1,2, \ldots, N\}$ such that each bidder's strategy maximizes her expected payoff taking as given the strategy functions of the other bidders:

$$
s_{i}\left(v_{i}\right)=\arg \max _{b_{i}} \mathbb{E}\left(1\left\{b_{i}>s_{j}\left(v_{j}\right) \forall j \neq i\right\} \quad\left[U\left(v_{i}, c\right)-b_{i}\right]\right)
$$

where the expectation is taken over the joint distribution of $\left\{v_{j}: j \neq i\right\}$ (and $c$, if this is not common knowledge). This BNE can be described as the solution to a system of differential equations.

Most empirical applications of structural auction models have focused on the Independent Private Values (IPV) model. This model assumes that valuations depend only on private information signals, $U\left(v_{i}, c\right)=v_{i}$, and they are independently and identically distributed, i.e., $\mathbf{F}\left(v_{1}, v_{2}, \ldots, v_{n}\right)=\prod_{i=1}^{N} F\left(v_{i}\right)$. It also imposes the restriction that the data come from a symmetric BNE: $s_{i}\left(v_{i}\right)=s\left(v_{i}\right)$ for every bidder $i$. A BNE of the IPV model can be described as a strategy function $s($.$) that solves the differential equation:$

$$
b_{i}=s\left(v_{i}\right)=v_{i}-\frac{F\left(v_{i}\right) s^{\prime}\left(v_{i}\right)}{(N-1) f\left(v_{i}\right)}
$$

subject to the boundary condition boundary $s(\underline{v})=\underline{v}$, and where $f$ is the density function of the distribution $F$. This differential equation has a unique solution that has a closed-form expression.

Auction data is widely available. In many countries, procurement auction data must be publicly available by law. Empirical researchers have used these data to answer different empirical questions such as detecting collusion among bidders, testing different auction models, or designing auction rules that maximize seller's revenue or total welfare.

The first empirical papers on auctions focused on testing important predictions of the model, without estimating the structural parameters (Hendricks and Porter, 1988; Hendricks, Porter, and Wilson, 1994; Porter, 1995). The papers by Paarsch $(1992,1997)$ and Laffont, Ossard, and Vuong (1995) present the first structural estimations of auction models.

In the structural estimation of auction models, the researcher has some information on bids and uses this information and the equilibrium conditions to estimate the distribution of bidders' valuations. Auction data may come in different forms, and this has important implications for the identification and estimation of the model. In an ideal situation, the researcher has a random sample of $T$ independent auctions (indexed by $t$ ) of the same type of object from the same population of bidders, and she observes the bids of each of the $N_{t}$ bidders at every auction $t$ in the sample. Such 
ideal situations are rare in practice. For instance, often the researcher observes only the winning bid. Also, it is common to have a sample of similar but heterogeneous auctions (e.g., different environments, or non identical objects) such that it is not plausible to assume that the same distribution of bidders' valuations, $F($.), applies to the $T$ auctions. In that case, it is useful to have observable auction characteristics, $X_{t}$, such that the researcher may assume that two auctions with the same observable characteristics have the same distributions of valuations: $F_{t}\left(v \mid X_{t}\right)=F\left(v \mid X_{t}\right)$ for every auction $t$. In general, an auction dataset can be described as $\left\{b_{t}^{(n)}, X_{t}: n=1, \ldots, \bar{N}_{t}\right.$; $t=1,2, \ldots, T\}$, where $b_{t}^{(1)}$ is the largest bid, $b_{t}^{(2)}$ is the second largest, and so on; and $\bar{N}_{t}$ is the number of bids the researcher observes in auction $t$. When the dataset includes only information on winning bids, we have that $\bar{N}_{t}=1$ for any auction $t$.

Tree planting procurement auctions in British Columbia. Paarsch (1992) studies first price sealedbid auctions of tree planting contracts operated by the Forest Service (government agency) in the province of British Columbia, Canada. The object of an auction is described by the number and type of trees to plant and the location. The bidding variable is the price per tree, and the winner of the auction is the firm with the lowest price. The dataset consists of 144 auctions in the same forest region between 1985 and 1988 with information on all the bids. Paarsch estimates structurally independent private value models and common value models under different parametric specifications of the distribution of firms' costs. All the specifications of private value models are rejected. However, the estimated common value models are consistent with observed bidders' behavior. More specifically, there is evidence consistent with bidders' concern for the winner's curse and with bid functions that increase with the number of bidders.

The first empirical applications on structural auction models consider parametric specifications of the distribution of valuations (Paarsch, 1992, 1997; Laffont, Ossard, and Vuong, 1995; Baldwin, Marshall, and Richard, 1997). However, the more recent literature has focused on the nonparametric identification and estimation of this distribution. Guerre, Perrigne, and Vuong (2000) show that equation (17), that characterizes the equilibrium of the model, implies that a bidder's valuation is a known function of his bid and the distribution of observed bids. Let $G(b)$ and $g(b)$ be the distribution and the density function of bids, respectively, implied by the equilibrium of the model. Since the equilibrium bidding strategy, $s\left(v_{i}\right)$, is strictly increasing, we have that $v_{i}=s^{-1}\left(b_{i}\right)$ and $G\left(b_{i}\right)=F\left(s^{-1}\left(b_{i}\right)\right)$, and this implies that $g\left(b_{i}\right)=f\left(v_{i}\right) / s^{\prime}\left(v_{i}\right)$. Substituting these expressions into the differential equation (17), we get:

$$
v_{i}=\xi\left(b_{i}, G\right)=b_{i}+\frac{G\left(b_{i}\right)}{(N-1) g\left(b_{i}\right)}
$$

Based on this equation, the distribution of valuations can be estimated from the data using a twostep procedure. Suppose for the moment that the data consists of a random sample of independent and identical auctions with information on all bids. Then, the distribution and density functions, 
$G$ and $g$, can be consistently estimated at any value $b \in[\underline{b}, \bar{b}]$ using nonparametric methods. In a second-step, we can use equation 18 to construct the estimated pseudo-values $\widehat{v}_{t}^{(n)}=\xi\left(b_{t}^{(n)}, \widehat{G}\right)$ and use them to obtain a nonparametric kernel estimator of the density of values $f(v)$ at any value $v \in[\underline{v}, \bar{v}]$. GPV show that the estimator can be easily generalized to datasets where only the winning bid is observed.

Athey and Haile (2002) provide a comprehensive treatment of the nonparametric identification of auction models. They show that the asymmetric IPV model is identified from data of winning bids if the identity of the winner is observed. When the distribution of values depends on observable auction characteristics, $F\left(v \mid X_{t}\right)$, they show that this distribution is identified from data of winning bids, both in the symmetric and the asymmetric IPV model. They also provide conditions for the identification of the affiliated private value model and the common values model.

In some applications, especially in procurement auctions, there may be substantial heterogeneity across auctions after controlling for observable characteristics, and not controlling for this heterogeneity can generate important biases in the estimated distributions of valuations. Krasnokutskaya (2011) and Asker (2010) propose and estimate auction models of IPV with unobserved auction heterogeneity. 18

In Krasnokutskaya's model, bidders' valuations have a multiplicative structure: $u_{i t}=v_{i t} * c_{t}$, where $v_{i t}$ is private information of bidder $i$ at auction $t$, and $c_{t}$ is common knowledge to all the bidders in auction $t$. She provides sufficient conditions for the nonparametric identification of the distribution of the two components, and proposes an estimation method 19 Krasnokutskaya applies her method to data from Michigan highway procurement auctions. She finds that, after conditioning on observable auction characteristics (e.g., number of bidders and project size), private information explains only $34 \%$ of the sample variation in winning bids. The remaining sample variation comes from unobserved heterogeneity from the point of view of the researcher. Estimates of the model that ignore this unobserved heterogeneity provide substantial biases in the average and the variance of firms' costs, and underestimate firms' mark-ups.

Asker (2010) considers a similar model where bidders' valuations have a multiplicative structure between IPVs and common knowledge auction heterogeneity. He applies this model to estimate the damages and efficiency costs of a "bidding ring" (cartel) in the US market for collectible stamps. Like Krasnokutskaya, he finds that accounting for unobserved auction heterogeneity has an important impact on the estimated model and its economic implications. The model without unobserved heterogeneity over-estimates the cartel's damages to the seller by more than 100\%, and under-estimates the efficiency loss from the cartel by almost $50 \%$.

\footnotetext{
${ }^{18}$ Their methods are based on Li and Vuong (1998) who propose a nonparametric procedure for estimating the densities of two additive unobservable random variables.

${ }^{19} \mathrm{~A}$ key (and very intuitive) identification condition is that the researcher observes multiple bids for each auction. Data with only winning bids is not sufficient.
} 
Haile and Tamer (2003) study the identification of the distribution of bidders's valuations in English auctions under more realistic conditions that the standard theoretical model. In the theoretical model, price increases continuously and each bidder pushes a button to exit the auction when the price reaches her valuation. In contrast, in actual English auctions, prices typically rise in jumps of varying sizes, bidders do not need not indicate whether they are "in" or "out" as the auction proceeds, and they can call out bids whenever they want. Haile and Tamer consider the identification of symmetric IPV English auctions under two weak conditions: bidders do not bid more than their valuations; and they do not allow an opponent to win at a price smaller than their valuation. They show that these restrictions provide informative bounds on the distribution function of valuations. This is one of the first studies in empirical IO on the application of moment inequalities to set identify structural parameters.

The recent literature on structural auction models has extended the standard model in important directions. Bajari and Hortacsu (2003), Li and Zheng (2009), Athey, Levin, and Seira (2011), Marmer, Shneyerov, and Xu (2013), and Gentry and Li (2014) study endogenous entry of bidders (and sellers). Jofre-Bonet and Pesendorfer (2003) and Groeger (2014) estimate dynamic structural models of procurement auctions with capacity constraints and sunk entry costs, respectively. Lu and Perrigne (2008), Guerre, Perrigne, and Vuong (2009), Campo et al. (2011) incorporate bidders' risk aversion, provide conditions for identification, and propose estimation methods. Finally, Lewis and Bajari (2011) and Takahashi (2014) study procurement auctions where the winner is determined by a scoring rule that weights both the price and the quality in a firm's bid.

\section{Conclusions}

Over the last three decades, researchers in empirical IO have generated useful models and methods to study demand, productivity, auctions, market power, contracts, and industry dynamics, as well as many other topics that we have not included in this survey. Important developments in structural microeconometrics have been originated in the context of dealing with empirical questions on market competition and firms' behavior. Many of these models and techniques have been 'exported' to other fields of empirical micro such as trade, urban, health, public, environmental, education, development, finance, and labor.

As mentioned in the Introduction, the increasing availability of larger and more detailed data sets has played a key role in the evolution of empirical IO during this period. In the current era of big data, we can only expect that this trend will continue in the future. Richer data will not be a substitute for structural models. On the contrary, as in the past, better data will make possible the estimation of more realistic and ambitious models of consumer behavior and firm competition. The increasing availability of randomized experiments on firms' competition will make the identification of these models more robust and reliable. 


\section{References}

[1] Acemoglu, D., P. Aghion, R. Griffith, and F. Zilibotti (2010): "Vertical integration and technology: Theory and evidence," Journal of the European Economics Association, 8(5), 989-1033.

[2] Ackerberg, D. A., and M. Botticini (2002): "Endogenous matching and the empirical determinants of contract form," Journal of Political Economy 110(3), 564-591.

[3] Ackerberg, D., K. Caves and G. Frazer (2015): "Identification Properties of Recent Production Function Estimators, " Econometrica, 83(6), 2411-2451.

[4] Aguirregabiria, V. (1999): "The dynamics of markups and inventories in retailing firms," The Review of Economic Studies, 66, 275-308.

[5] Aguirregabiria, V., and C. Alonso-Borrego (2014): "Labor contracts and flexibility: evidence from a labor market reform in Spain," Economic Inquiry, 52(2), 930-957.

[6] Aguirregabiria, V. and C-Y. Ho (2012): "A dynamic oligopoly game of the US airline industry: Estimation and policy experiments," Journal of Econometrics, 68, 156-173.

[7] Aguirregabiria, V., and P. Mira (2002): "Swapping the Nested Fixed Point Algorithm: A Class of Estimators for Discrete Markov Decision Models," Econometrica, 70, 1519-1543.

[8] Aguirregabiria, V., and P. Mira (2007): "Sequential estimation of dynamic discrete games," Econometrica 75(1), 1-53.

[9] Anand, B., and T. Khanna (2000): "The structure of licensing contracts," Journal of Industrial Economics 48, 103-135.

[10] Arcidiacono, P. and R. Miller (2011): "Conditional choice probability estimation of dynamic discrete choice models with unobserved heterogeneity," Econometrica, 79(6), 1823-1867.

[11] Arellano, M., and S. Bond (1991): "Some Tests of Specification for Panel Data: Monte Carlo Evidence and an Application to Employment Equations," The Review of Economic Studies, $58(2), 277-297$.

[12] Arrow, K. J., H. B. Chenery, B. S. Minhas, and R. M. Solow (1961): "Capital-Labor Substitution and Economic Efficiency," The Review of Economics and Statistics, 43(3), 225-250.

[13] Asker, J. (2010): "A Study of the Internal Organization of a Bidding Cartel", American Economic Review, 100(3), 724-762.

[14] Athey, S. and P. Haile (2002): "Identification of Standard Auction Models," Econometrica, $70(6), 2107-2140$.

[15] Athey, S., J. Levin, and E. Seira (2011): "Comparing open and sealed bid auctions: Evidence from timber auctions," Quarterly Journal of Economics, 126(1), 207-257.

[16] Bacon, R. (1991): "Rockets and feathers: The asymmetric speed of adjustment of UK retail gasoline prices to cost changes," Energy Economics 13, 211-218. 
[17] Bai, C.-E., Z. Tao, and C. Wu (2004): "The control of technology alliances: An empirical analysis of the biotechnology industry," RAND Journal of Economics 35(2), 277-305.

[18] Bajari, P., L. Benkard and J. Levin (2007): "Estimating dynamic models of imperfect competition," Econometrica, 75, 1331-1370.

[19] Bajari, P. and A. Hortacsu (2003): "The Winner's Curse, Reserve Prices and Endogenous Entry: Empirical Insights from eBay Auctions," Rand Journal of Economics, 3(2), 329-355.

[20] Baker, G. P., and T. N. Hubbard (2004): "Contractability and asset ownership: On-board competers and governance," Quarterly Journal of Economics 119(4), 1443-1479.

[21] Baldwin, L., R. Marshall, and J.-F. Richard (1997): "Bidder Collusion in U.S. Forest Service Timber Sales," Journal of Political Economy, 105, 657-699.

[22] Berndt, E., M. Fuss, and L. Waverman (1977): "Dynamic models of the industrial demand for energy," Technical report, Electric Power Institute.

[23] Bernheim, D., and M. D. Whinston (1990): "Multimarket contact and collusive behavior," RAND Journal of Economics 21(1), 1-26.

[24] Berry, S. (1992): "Estimation of a Model of Entry in the Airline Industry," Econometrica, 60, 889-917.

[25] Berry, S. T. (1994): "Estimating discrete-choice models of product differentiation," RAND Journal of Economics 25(2), 242-262.

[26] Berry, S. T., and P. A. Haile (2014): "Identification in differentiated products markets using market level data," Econometrica, 82(5), 1749-1797.

[27] Berry, S., J. Levinsohn, and A. Pakes (1995): "Automobile prices in market equilibrium," Econometrica 63(4), 841-890.

[28] Berry, S., J. Levinsohn, and A. Pakes (2004): "Differentiated products demand systems from a combination of micro and macro data: The new car market," Journal of Political Economy 112(1), 68-105.

[29] Berto Villas-Boas, S. (2007): "Vertical Relationships Between Manufacturers and Retailers: Inference with Limited Data," Review of Economic Studies, 74(2), 625-652.

[30] Bitlet, M. P., T. J. Moskowitz, and A. Vissing-Jorgenson (2005): "Testing agency theory with entrepreneur effort and wealth," Journal of Finance 60(2), 539-576.

[31] Bloom, N., M. Schankerman, and J. Van Reenen (2013): "Identifying technology spillovers and product market rivalry," Econometrica, 81(4), 1347-1393.

[32] Blundell, R., and S. Bond (1998): "Initial conditions and moment restrictions in dynamic panel data models," Journal of Econometrics, 87, 115-143.

[33] Blundell, R., and S. Bond (2000): "GMM estimation with persistent panel data: an application to production functions," Econometric Reviews, 19(3), 321-340. 
[34] Bolle, F., and W. Guth (1992): "Competition among mutually dependent sellers," Journal of Institutional and Theoretical Economics 148(2), 209-239.

[35] Bonnet, C. and P. Dubois, (2010): "Inference on Vertical Contracts between Manufacturers and Retailers Allowing for Nonlinear Pricing and Resale Price Maintenance," RAND Journal of Economics, 41(1), 139-164.

[36] Borenstein, S., A. Cameron, and R. Gilbert (1997): "Do gasoline prices respond asymmetrically to crude oil price changes," Quarterly Journal of Economics 112, 305-339.

[37] Brander, J. A., and A. Zhang (1990): "Market conduct in the airline industry: An empirical investigation," RAND Journal of Economics 21(4), 567-583.

[38] Brendstrup, B., H. J. Paarsch, and J. Solow (2006): "Estimating market power in the presence of capacity constraints: An application to high-fructose corn sweetener," International Journal of Industrial Organization 24, 251-267.

[39] Brenkers, R. and Verboven, (2006): "Liberalizing a Distribution System: The European Car Market," Journal of the European Economic Association, 4(1), 216-251.

[40] Bresnahan, T. F. (1982): "The oligopoly solution concept is identified," Economics Letters $10,87-92$.

[41] Bresnahan, T. F. (1987): "Competition and collusion in the American automobile industry: The 1955 price war," Journal of Industrial Economics 35(4), 457-482.

[42] Bresnahan, T. and P. Reiss (1990): "Entry into Monopoly Markets," Review of Economic Studies, 57, 531-553.

[43] Bresnahan, T. and P. Reiss (1991): "Entry and Competition in Concentrated Markets," Journal of Political Economy, 95, 977-1009.

[44] Bresnahan, T. F., and R. Schmalensee, eds. (1987) The Empirical Renaissance in Industrial Economics, volume 35, Wiley, special issue of The Journal of Industrial Economics.

[45] Brickley, J. A. (2002): "Royalty rates and upfront fees in share contracts: Evidence from franchising," Journal of Law, Economics, and Organization 18(2), 511-535.

[46] Brickley, J. A., and F. H. Dark (1987): "The choice of organizational form," Journal of Financial Economics 18, 401-420.

[47] Campo, S., E. Guerre, I. Perrigne, and Q. Vuong (2011): "Semiparametric estimation of first-price auctions with risk-averse bidders," Review of Economic Studies, 78(1), 112-147.

[48] Christensen, L., D. Jorgenson, and L. Lau (1971): "Conjugate duality and the transcendental logarithmic production function," Econometrica, 39, 255-256.

[49] Chu, C. S. (2010): "The effects of satellite entry on cable television prices and product quality," RAND Journal of Economics 41(4), 730-764.

[50] Ciliberto, F., and J. W. Williams (2014): "Does multimarket contact facilitate tacit collusion? Inference on conduct parameters in the airline industry," RAND Journal of Economics 45(4), 764-791. 
[51] Clark, R., and J.-F. Houde (2014): "The effect of explicit communication on pricing: Evidence from the collapse of a gasoline cartel," Journal of Industrial Economics 62(2), 191-228.

[52] Collard-Wexler, A. (2013): "Demand Fluctuations in the Ready-Mix Concrete Industry," Econometrica, 81(3), 1003-1037.

[53] Collard-Wexler, A., and J. De Loecker (2014): "Reallocation and technology: evidence from the US steel industry," American Economic Review, 105(1), 131-171.

[54] Corts, K. S. (1999): "Conduct parameters and the measurement of market power," Journal of Econometrics 88, 227-250.

[55] Crawford, G. S. (2012): "Endogenous product choice: A progress report," International Journal of Industrial Organization 30, 315-320.

[56] Crawford, G.S. and Yurukoglu, A. (2012): "The Welfare Effects of Bundling in Multichannel Television Markets," American Economic Review, 102(2), 643-685.

[57] Das, M. (1992): "A Micro-econometric Model of Capital Utilization and Retirement: The Case of the Cement Industry," Review of Economic Studies, 59, 277-297.

[58] Davis, P. (2006): "Competition in retail markets: Movie theaters," RAND Journal of Economics 37(4), 964-982.

[59] Deaton, A., and J. Muellbauer (1980): "An almost ideal demand system," American Economic Review 70(3), 321-325.

[60] De Loecker, J. (2011): "Product differentiation, multiproduct firms, and estimating the impact of trade liberalization on productivity," Econometrica, 79(5), 1407-1451.

[61] Deltas, G. (2008): "Retail gasoline pricing and local market power," Journal of Industrial Economics 56(3), 613-628.

[62] Doraszelski, U., and J. Jaumandreu (2013): "R\&D and Productivity" Estimating Endogenous Productivity," Review of Economic Studies, 80 (4): 1338-1383.

[63] Draganska, M., M. Mazzeo, and K. Seim (2009): "Beyond plain vanilla: Joint product assortment and pricing decisions," Quantitative Marketing and Economics 7, 105-146.

[64] Dube, J.P. (2004): "Multiple discreteness and product differentiation: Demand for carbonated soft drinks," Marketing Science 23(1), 66-81.

[65] Dube, J.P. (2005): "Product differentiation and mergers in the carbonated soft drink industry," Journal of Economics and Management Science 14(4), 879-904.

[66] Dunne, T., S. Klimek, M. Roberts, and D. Xu (2013): "Entry, Exit and the Determinants of Market Structure," RAND Journal of Economics, 44(3), 462-487.

[67] Eckert, A. (1999): "A Study of Canadian Retail Gasoline Prices," Ph.D. thesis, University of British Columbia.

[68] Eckert, A. (2003): "Retail price cycles and the presence of small firms," International Journal of Industrial Organization 21, 151-170. 
[69] Einav, L. (2010): "Not all rivals look alike: Estimating an equilibrium model of the release date timing game," Economic Inquiry, 48(2), 369-390.

[70] Elfenbein, D., and J. Lerner (2003): "Ownership and control rights in internet portal alliances," RAND Journal of Economics 34, 356-369.

[71] Ellickson, P. and S. Misra (2008): "Supermarket Pricing Strategies," Marketing Science, $27(5), 811-828$.

[72] Erdem, T., S. Imai and M. P. Keane (2003): "Brand and Quantity Choice Dynamics under Price Uncertainty," Quantitative Marketing and Economics, 1, 5-64.

[73] Ericson, R. and A. Pakes (1995): "Markov Perfect Industry Dynamics: A Framework for Empirical Work," Review of Economic Studies, 62, 53-82.

[74] Fan, Y. (2013): "Ownership consolidation and product characteristics: A study of the US daily newspaper market," American Economic Review 103(5), 1589-1628.

[75] Forbes, S. J., and M. Lederman (2013): "Contract form and technology adoption in network industries," Journal of Law, Economics, and Organization 29(2), 385-413.

[76] Fox, J. T., K. Kim, S. P. Ryan, and P. Bajari (2011): "A simple estimator for the distribution of random coefficients," Quantitative Economics 2(3), 381-418.

[77] Fox, J. T., K. Kim, S. P. Ryan, and P. Bajari (2012): "The random coefficients logit model is identified," Journal of Econometrics 166(2), 204-212.

[78] Gandhi, A., S. Navarro, and D. Rivers (2016): "On the Identification of Production Functions: How Heterogeneous is Productivity?," manuscript. Western University.

[79] Gasmi, F., J.-J. Laffont, and Q. Vuong (1992): "Econometric analysis of collusive behavior in a soft drink market," Journal of Economics and Management Strategy 1, 277-311.

[80] Genesove, D., and W. P. Mullin (1998): "Testing static oligopoly models: Conduct and cost in the sugar industry, 1890-1914," RAND Journal of Economics 29(2), 355-377.

[81] Gentry, M., and T. Li (2014): "Identification in auctions with selective entry," Econometrica, $82(1), 315-344$.

[82] Gil, R., and F. Lafontaine (2012): "Using revenue sharing to implement flexible prices: Evidence from movie exhibition contracts," Journal of Industrial Economics 60, 187-214.

[83] Goettler, R. and B. Gordon (2011): "Does AMD spur Intel to innovate more?," Journal of Political Economy, 119(6), 1141-1200.

[84] Gorman, W. T. (1971): "Two stage budgeting," Mimeo.

[85] Gould, E. D., P. Pashigan, and C. J. Prendergast (2005): "Contracts, externalities, and incentives in shopping malls," Review of Economics and Statistics 87(3), 411-422.

[86] Gowrisankaran, G., A. Nevo, and R. Town, (2015): "Mergers When Prices are Negotiated: Evidence from the Hospital Industry," American Economic Review, 105(1), 172-203. 
[87] Gowrisankaran, G. and M. Rysman (2012): "Dynamics of Consumer Demand for New Durable Goods," Journal of Political Economy, 120, 1173-1219.

[88] Green, E., and R. H. Porter (1984): "Noncooperative collusion under imperfect price information," Econometrica 52(1), 87-100.

[89] Grieco, P., S. Li, and H. Zhang (2016): "Production function estimation with unobserved input price dispersion," International Economic Review, 57(2), 665-690.

[90] Grieco, P., J. Pinkse, and M. Slade (2016): "Brewed in North America: Mergers, marginal costs, and efficiency," UBC mimeo.

[91] Griliches, Z., and J. Mairesse (1999): "Production Functions: The Search for Identification," in Steinar Strom (ed.), Econometrics and Economic Theory in the 20th Century: The Ragnar Frisch Centennial Symposium, Econometric Society Monograph Series 31, Cambridge University Press.

[92] Groeger, J. (2014): "A study of participation in dynamic auctions," International Economic Review, 55(4), 1129-1154.

[93] Grossman, S. J., and O. D. Hart (1986): "The costs and benefits of ownership: A theory of vertical and lateral integration," Journal of Political Economy 94(4), 691-719.

[94] Gu, W., and W. Wang (2013): "Correction for variations in capacity utilization in the measurement of productivity growth: A nonparametric approach," Journal of Economic and Social Measurement, 38, 347-369.

[95] Guerre, E., I. Perrigne, and Q. Vuong (2000): "Optimal Nonparametric Estimation of FirstPrice Auctions," Econometrica, 68, 525-574.

[96] Guerre, E., I. Perrigne, and Q. Vuong (2009): "Nonparametric Identification of Risk Aversion in First-Price Auctions Under Exclusion Restrictions," Econometrica, 77(4), 1193-1227.

[97] Haile, P. A., and E. Tamer (2003): "Inference with an incomplete model of English auctions," Journal of Political Economy, 111(1), 1-51.

[98] Handel, B. R. (2013): "Adverse selection and inertia in health insurance markets: When nudging hurts," American Economic Review 103(7), 2643-2682.

[99] Hart, O. D., and J. Moore (1990): "Property rights and the nature of the firm," Journal of Political Economy 98(6), 1119-1158.

[100] Hausman, J., G. Leonard, and J. D. Zona (1994): "Competitive analysis with differentiated products," Annales d'Economie et de Statistique 34, 159-180.

[101] Hendel, E. (1999): "Estimating multiple discrete-choice models: An application to computerization returns," The Review of Economic Studies 66(2), 423-446.

[102] Hendel, I., and A. Nevo (2006): "Measuring the Implications of Sales and Consumer Inventory Behavior. Econometrica 74, 1637-1674.

[103] Hendricks, K., M. Piccione and G. Tan (1997): "Entry and Exit in Hub-Spoke Networks," The RAND Journal of Economics, 28, 291-303. 
[104] Hendricks, K., and R. Porter (1988): "An Empirical Study of an Auction with Asymmetric Information," American Economic Review, 78 (5), 865-883.

[105] Hendricks, K, R. Porter, and C. Wilson (1994): "Auctions for Oil and Gas Leases with an Informed Bidder and a Random Reservation Price," Econometrica, 62, 1415-1444.

[106] Holmes, T. (2011): "The Diffusion of Wal-Mart and Economies of Density," Econometrica, $79(1), 253-302$.

[107] Holmstrom, B. (1979): "Moral hazard and observability," The Bell Journal of Economics 10(1), 74-91.

[108] Holmstrom, B. (1982): "Moral hazard in teams," Bell Journal of Economics 13(2), 324-340.

[109] Holmstrom, B., and P. Milgrom (1991): "Multitask principal-agent analyses: Incentive contracts, asset ownership, and job design," Journal of Law, Economics, and Organization 7, $24-52$.

[110] Holmstrom, B., and P. Milgrom (1994): "The firm as an incentive system," American Economic Review 84(4), 972-991.

[111] Hosken, D., and D. Reiffen (2004): "Patterns of retail price variation," RAND Journal of Economics, 35(1), 128-146.

[112] Hotelling, H. (1929): "Stability in competition," The Economic Journal 39(153), 41-57.

[113] Hotz, J., and R.A. Miller (1993): "Conditional choice probabilities and the estimation of dynamic models," Review of Economic Studies, 60, 497-529.

[114] Houde, J.-F. (2012): "Spatial differentiation and vertical mergers in retail markets for gasoline," American Economic Review 102(5), 2147-2182.

[115] Igami, M. (2017): "Estimating the Innovator's Dilemma: Structural Analysis of Creative Destruction in the Hard Disk Drive Industry, 1981-1998," Journal of Political Economy, forthcoming.

[116] Igami, M., and N. Yang (2016): "Unobserved Heterogeneity in Dynamic Games: Cannibalization and Preemptive Entry of Hamburger Chains in Canada," Quantitative Economics, $7(2), 483-521$.

[117] Iwata, G. (1974): "Measurement of conjectural variations in oligopoly," Econometrica 42, 947-966.

[118] Jofre-Bonet, M. and M. Pesendorfer (2003): "Estimation of a Dynamic Auction Game," Econometrica, 71, 1443-1489.

[119] Jorgenson, D. and Z. Griliches (1967): "An explanation of productivity change," The Review of Economic Studies, 34(3), 249-283.

[120] Joskow, P. (1985): "Vertical integration and long term contracts: The case of coal-burning electric generation plants," Journal of Law, Economics, and Organization 1(1), 33-80. 
[121] Joskow, P. (1987): "Contract duration and relationship-specific investment: Empirical evidence from coal markets," American Economic Review 77, 168-185.

[122] Kalouptsidi, M. (2014): "Time to build and fluctuations in bulk shipping," American Economic Review, 104(2), 564-608.

[123] Kano, K. (2013): "Menu Costs and Dynamic Duopoly," International Journal of Industrial Organization, 31(1), 102-118.

[124] Kasahara, H. (2009): "Temporary Increases in Tariffs and Investment: The Chilean Case," Journal of Business and Economic Statistics, 27(1), 113-127.

[125] Kasahara, H., and K. Shimotsu (2008): "Nonparametric Identification of Finite Mixture Models of Dynamic Discrete Choices," Econometrica, 77(1), 2009, 135-175.

[126] Kennet, M. (1994): "A Structural Model of Aircraft Engine Maintenance," Journal of Applied Econometrics, 9, 351-368.

[127] Kmenta, J. (1967): "On Estimation of the CES Production Function," International Economic Review, 8(2), 180-189.

[128] Krasnokutskaya, E. (2011): "Identification and Estimation in Procurement Auctions under Unobserved Auction Heterogeneity," Review of Economic Studies, 78(1), 293-327.

[129] Laffont, J., H. Ossard, and Q. Vuong (1995): "Econometrics of first-price auctions," Econometrica, 63, 953-980.

[130] Lafontaine, F. (1992): "Agency theory and franchising: Some empirical results," RAND Journal of Economics 23(2), 263-283.

[131] Lafontaine, F., and K. Shaw (1999): "The dynamics of franchise contracting: Evidence from panel data," Journal of Political Economy 107(5), 1041-1080.

[132] Lafontaine, F., and M. E. Slade (1996): "Retail contracting and costly monitoring: Theory and evidence," European Economic Review 40(3-5), 923-932.

[133] Lafontaine, F., and M. E. Slade (2007): "Vertical integration and firm boundaries: The evidence," Journal Economic Literature 45, 629-685.

[134] Lafontaine, F., and M. E. Slade (2012): "Contracting between firms: Evidence," in R. Gibbons and J. Roberts, eds., Handbook of Organizational Economics, chapter 24, pp. 958-1013, Princeton University Press.

[135] Lancaster, K. (1978): "Socially optimal product differentiation," American Economic Review $65(4), 567-585$.

[136] Lerner, J., and R. P. Merges (1998): "The control of technology alliances: An empirical analysis of the biotechnology industry," Journal of Industrial Economics 46(2), 125-156.

[137] Levinsohn, J., and A. Petrin (2003): "Estimating Production Functions Using Inputs to Control for Unobservables," Review of Economic Studies , 70, 317-342. 
[138] Lewis, M. S. (2009): "Temporary wholesale gasoline price spikes have long-lasting retail effects: The aftermath of hurricane Rita," Journal of Law and Economics 52(3), 581-605.

[139] Lewis, G., and P. Bajari (2011): "Procurement contracting with time incentives: Theory and evidence," Quarterly Journal of Economics, 126(3), 1173-1211.

[140] Li, T., and Q. Vuong (1998): "Nonparametric estimation of the measurement error model using multiple indicators," Journal of Multivariate Analysis, 65(2), 139-165.

[141] Li, T., and X. Zheng (2009): "Entry and competition effects in first-price auctions: theory and evidence from procurement auctions," Review of Economic Studies, 76(4), 1397-1429.

[142] Lu, J., and I. Perrigne (2008): "Estimating risk aversion from ascending and sealed-bid auctions: the case of timber auction data," Journal of Applied Econometrics, 23(7), 871-896.

[143] Lychagin, S., J. Pinkse, M. Slade, and J. Van Reenen (2015): "Spillovers in space: Does geography matter?" Journal of Industrial Economics, 64(2), 295-335.

[144] Marmer, V., A. Shneyerov, and P. Xu (2013): "What model for entry in first-price auctions? A nonparametric approach," Journal of Econometrics, 176 (1), 46-58.

[145] Marschak, J., and Andrews, W. H. (1944): "Random simultaneous equations and the theory of production," Econometrica, 12, 143-205.

[146] Maskin, E. and Tirole, J. (1988a): "A Theory of Dynamic Oligopoly, I: Overview and Quantity Competition with Large Fixed Costs," Econometrica, 56, 549-569.

[147] Maskin, E. and Tirole, J. (1988b): "A Theory of Dynamic Oligopoly, II: Price Competition, Kinked Demand Curves, and Edgeworth Cycles," Econometrica, 56, 571-599.

[148] Masten, S. E. (1984): "The organization of production: Evidence from the aerospace industry," Journal of Law and Economics 27(2), 403-417.

[149] Mazzeo, M. (2002): "Product choice and oligopoly market structure," RAND Journal of Economics, 33 (2), 221-42.

[150] McFadden, D. (1978): "The general linear profit function," in M. Fuss and D. McFadden, eds., Production Economics: A Dual Approach to Theory and Applications, pp. 269-286, North Holland.

[151] Michel, C. (2016): "Identification and estimation of intra-firm and industry competition via ownership change," Universitat Pompeu Fabra.

[152] Midrigan, V. (2011): "Menu costs, multiproduct firms, and aggregate fluctuations," Econometrica, 79(4), 1139-1180.

[153] Miller, N. H., and M. C. Weinberg (2016): "The market power effects of a merger: Evidence from the US brewing industry," Georgetown University.

[154] Mortimer, J. H. (2008): "Vertical contracts in the video rental industry," Review of Economic Studies 75, 165-199. 
[155] Nakamura, E., and J. Steinsson (2008): "Five facts about prices: A reevaluation of menu cost models," Quarterly Journal of Economics, 123(4), 1415-1464.

[156] Nevo, A. (1998): "Identification of the oligopoly solution concept in a differentiated-products industry," Economics Letters 59, 391-395.

[157] Nevo, A. (2000): "Mergers with differentiated products: The case of the ready-to-eat cereal industry," RAND Journal of Economics 31(3), 395-421.

[158] Nevo, A. (2001): "Measuring market power in the ready-to-eat cereal industry," Econometrica 69(2), 307-342.

[159] Noel, M. (2007): "Edgeworth price cycles, cost-based pricing, and sticky pricing in retail gasoline markets," Review of Economics and Statistics 89(2), 324-334.

[160] Norton, S. W. (1988): "An empirical look at franchising as an organizational form," Journal of Business 61(2), 197-218.

[161] Olley, S., and A. Pakes (1996): "The Dynamics of Productivity in the Telecommunications Equipment Industry", Econometrica, 64, 1263-97.

[162] Paarsch, H. (1992): "Deciding between the common and private value paradigms in empirical models of auctions," Journal of Econometrics, 51, 191-215.

[163] Paarsch, H. (1997): "Deriving an estimate of the optimal reserve price: An application to British Columbian timber sales," Journal of Econometrics, 78, 333-57.

[164] Pakes, A. (1986): "Patents as Options: Some Estimates of the Value of Holding European Patent Stocks," Econometrica, 54, 755-784.

[165] Pesendorfer, M. (2002): "Retail Sales: A Study of Pricing Behavior in Supermarkets," Journal of Business, 75(1), 33-66.

[166] Petrin, A. (2002): "Quantifying the benefits of new products: The case of the minivan," Journal of Political Economy 110(4), 705-729.

[167] Pinkse, J., and M. Slade (2004): "Mergers, brand competition, and the price of a pint," European Economic Review 48(3), 617-643.

[168] Pinkse, J., M. Slade, and C. Brett (2002): "Spatial price competition: A semiparametric approach," Econometrica 70(3), 1111-1153.

[169] Porter, R. H. (1983): "A study of cartel stability: The Joint Executive Committee, 18801886," Bell Journal of Economics 14(3), 301-314.

[170] Porter, R. (1995): "The Role of Information in U.S. Offshore Oil and Gas Lease Auction," Econometrica, 63(1), 1-27.

[171] Rennhoff, A., and M. Owens (2012): "Competition and the Strategic Choices of Churches," American Economic Journal: Microeconomics, 4(3), 152-170.

[172] Reynolds, R. J., and B. R. Snapp (1986): "The competitive effects of partial equity interests and joint ventures," International Journal of Industrial Organization 4(2), 141-153. 
[173] Roberts, M. (1984): "Testing oligopolistic behavior," International Journal of Industrial Organization 2, 367-383.

[174] Roberts, M. and J. Tybout (1997): "The Decision to Export in Colombia: An Empirical Model of Entry with Sunk Costs," American Economic Review, 87(4), 545-564.

[175] Robinson, P. (1988): "Root-N-consistent semiparametric regression," Econometrica, 56(4), 931-954.

[176] Rota, P. (2004): "Estimating labor demand with fixed costs," International Economic Review, $45(1), 25-48$.

[177] Rust, J. (1987): "Optimal replacement of GMC bus engines: An empirical model of Harold Zurcher," Econometrica, 55, 999-1033.

[178] Ryan, Stephen P. "The costs of environmental regulation in a concentrated industry," Econometrica, 80(3), 1019-1061.

[179] Schiraldi, P. (2011): "Automobile replacement: a dynamic structural approach," RAND Journal of Economics, 42(2), 266-291.

[180] Seim, K. (2006): "An Empirical Model of Firm Entry with Endogenous Product-Type Choices," RAND Journal of Economics 37(3).

[181] Slade, M. E. (1989): "Price wars in price setting supergames," Economica 56, 295-310.

[182] Slade, M. E. (1992): "Vancouver's gasoline price wars: An empirical investigation in uncovering supergame strategies," Review of Economic Studies 59(2), 257-276.

[183] Slade, M. E. (1996): "Multitask agency and contract choice: An empirical exploration," International Economic Review 37(2), 465-486.

[184] Slade, M. (1998): "Optimal Pricing with Costly Adjustment: Evidence from Retail Grocery Stores," Review of Economic Studies, 65, 87-108.

[185] Slade, M. E. (2004): "Market power and joint dominance in UK brewing," Journal of Industrial Economics 48(1), 133-163.

[186] Spiller, P. T., and E. Favaro (1984): "The effects of entry regulation on oligopolistic interaction: The Uruguayan banking sector," RAND Journal of Economics 15, 244-254.

[187] Suzuki, J. (2013): "Land Use Regulation as a Barrier to Entry," International Economic Review, 54(2), 495-523.

[188] Sweeting, A. (2013): "Dynamic product positioning in differentiated product markets: The effects of fees for musical performance rights on the commercial radio industry," Econometrica 81(5), 1763-1803.

[189] Takahashi, H. (2014): "Strategic Design under Uncertain Evaluations: Theory and Evidence from Design-Build Auctions," manuscript. University of Mannheim.

[190] Varian, H. (1980): "A model of sales," The American Economic Review, 70(4), 651-659. 
[191] Wang, Z. (2009): "(Mixed) strategy in oligopoly pricing: Evidence from gasoline price cycles before and under a timimg regulation," Journal of Political Economy 117(6), 987-1030.

[192] Williamson, O. E. (1975): "Markets and Hierarchies: Analysis and Antitrust Implications," New York, NY: Free Press.

[193] Williamson, O. E. (1979): "Transaction cost economics: The governance of contractual relations," Journal of Law and Economics 22(2), 233-261.

[194] Wooldridge, J. (2009): "On estimating firm-level production functions using proxy variables to control for unobservables," Economics Letters, 104(3), 112-114. 


\section{Appendix}

Table 1: A Classification of Contracts

\begin{tabular}{|c|c|c|c|}
\hline & $\alpha=0$ & $0<\alpha<1$ & $\alpha=1$ \\
\hline \multicolumn{4}{|l|}{ Model: } \\
\hline $\begin{array}{r}\text { Agency } \\
\text { Market Organization }\end{array}$ & Vertical Integration & Revenue Shared & Market Transaction \\
\hline $\begin{array}{r}\text { Property Rights } \\
\text { Residual Decision Rights }\end{array}$ & To Principal & Shared & To Agent \\
\hline \multicolumn{4}{|l|}{ Contract Characteristics: } \\
\hline Who bares the Risk? & Principal & Shared & Agent \\
\hline Effort incentives for Agent & Low & Intermediate & High \\
\hline Effort incentives for Principal & High & Intermediate & Low \\
\hline Investment incentives for Agent & Low & Intermediate & High \\
\hline Investment incentives for Principal & High & Intermediate & Low \\
\hline
\end{tabular}

$\alpha$ is the share of output or revenue that the agent receives (agency models)

$\alpha$ is the allocation of control or residual decision rights to the agent (property rights models) 